\title{
Improving the resistance to hydrothermal ageing of flame-retarded PLA by incorporating miscible PMMA
}

\author{
R. Mangin ${ }^{\text {a, b }}$, H. Vahabi ${ }^{\text {a, }}{ }^{*}$, R. Sonnier ${ }^{b}$, C. Chivas-Joly ${ }^{c}$, J.-M. Lopez-Cuesta ${ }^{\text {b }}$, M. Cochez ${ }^{\text {a }}$ \\ ${ }^{a}$ Université de Lorraine, Laboratoire MOPS E.A. 4423, Metz F, 57070, France \\ ${ }^{\mathrm{b}}$ C2MA - Mines D'Alès, 30100, Alès, France \\ ' Laboratoire National de Métrologie et D'Essais (LNE), 78197, Trappes Cedex, France
}

\begin{abstract}
A B S T R A C T
Three flame-retarded systems based on PLA, PMMA and PLA/PMMA blend have undergone hydrothermal ageing. The miscibility of the blend as well as the crystallization behaviour of PLA were studied by DSC. The impact of ageing in terms of weight variations, melt viscosity, molecular weight distribution, morphology, and thermal degradation was investigated. Results showed that crystallization of PLA and significant hydrolysis phenomenon occurred during ageing. Flame retardant content determined by EDX and ICP revealed a loss of phosphorus during ageing, especially for flame-retarded PLA (91 wt\% phosphorus loss after ageing). Incorporation of $50 \mathrm{wt} \%$ PMMA moderated the negative impacts observed. Fire properties evaluated using cone calorimeter revealed almost no impact of ageing on flame-retarded PMMA, contrary to flame-retarded PLA (increase of pHRR from 291 to $487 \mathrm{~kW} / \mathrm{m}^{2}$ ). Flame-retarded blend shows intermediate properties. It revealed the positive effect of incorporation of PMMA in PLA, by limiting the water diffusion and by reducing the loss of phosphorus.
\end{abstract}

Keywords:

Poly (lactic acid)/poly(methyl methacrylate)

blend

Ageing

Fire properties

\section{Introduction}

The concerns about current environmental issues have led to a large increase in biopolymers production since the last decade [1]. Academia and industry researchers created new materials that seem to be an appropriate alternative to petroleum-based polymers. Among these biopolymers, polylactic acid (PLA) is bio-based and biodegradable. Its production capacities are predicted to grow by $50 \%$ by 2022 , compared to 2017 [2]. PLA shows interesting properties, including good mechanical and barrier properties, a high degree of transparency, as well as cost-effectiveness and easy processing [3-8]. Up to now, its main application is packaging, but it is also used in biomedicine [9], 3D printing [10], textiles [11], electronics [12] or automobile [13]. Hence, several studies and new developments have been performed in order to use PLA as substitution for oil-based polymers like polypropylene (PP) [14], polyethylene (PE) [15], polystyrene (PS) [16] or polyethylene terephthalate (PET) [16]. However, PLA shows two main drawbacks for various applications: its sensitivity to hydrolysis [17-20] and its reaction to fire, needing the use of flame retardants [21].

\footnotetext{
* Corresponding author.

E-mail address: henri.vahabi@univ-lorraine.fr (H. Vahabi).
}

Several studies showed that in the presence of water, hydrolysis processes occur, leading to a drastic decrease in molecular weight and therefore to degradation of the mechanical properties $[20,22,23]$. The process occurs in the presence of high relative humidity, and is more significant when polymer is completely immersed into water [24,25]. Henton et al. [17] described four key features that mark the hydrolysis phenomenon: the catalysis of the ester hydrolysis by carboxylic acid end groups of PLA during the degradation (autocatalysis), accelerated chain-end scission by low $\mathrm{pH}$ values, decreased sensitivity of crystalline regions to hydrolysis compared to amorphous regions, and a higher rate of hydrolysis at high temperature, especially above the glass transition temperature [26]. Some attempts have been made to reduce this water sensitivity. One of them may consists in mixing PLA with another polymer, which shows better water resistance. Poly (methyl methacrylate) (PMMA) is a good candidate, which is largely used, and which possesses strong mechanical properties as well as very good transparency. For a decade, some studies performed on PLA/ PMMA blend [27-30], which revealed a high degree of miscibility between the two components, and increased hydrolytic stability. Such blend has been commercially developed [31].

Polymers are used in many industrial sectors and applications, but their reaction to fire is still a great concern. Flame retardants 
(FRs) may be introduced into polymers in order to improve their fire behaviour, either by addition via melt blending (physical method), by direct incorporation into polymer structure (chemical method) or by application of a FR surface protective layer (coating). In FR composites, ageing may impact not only the polymeric matrix, by chain scission or crosslinking reactions, but also the FR system (chemical degradation, release of fillers by thermal migration, solubilization and leaching) [32]. Effects depend on the ageing conditions, the polymeric matrix, and the FR composition (mainly consisted of mineral fillers, or based on phosphorus, halogen or nitrogen compounds). Investigations concerning epoxy based intumescent coating have shown that in presence of water, ammonium polyphosphate (APP) turns into polyphosphoric acid, more soluble in water. In that case, the ageing had a huge impact on the FR system [33]. I n the opposite, new flame retardants have been designed, that keep their efficiency even after artificial weathering [34]. It has been shown that incorporation of brominated FR accelerates the photodegradation of polystyrene and polypropylene, revealing an impact on polymeric structures $[35,36]$. Other tests performed on various flame-retarded polymeric materials showed that polymeric surface was most impacted by artificial weathering. Hence, if flame retardancy occurs through a surface mechanism, like for intumescent system, fire properties are degraded [37]. Concerning PLA, its flame retardancy has been widely investigated [21,38-44]. Particularly, degradation of PLA under hygrothermal ageing was shown to be accelerated in presence of flame retardants, especially when nanoclays were incorporated [38]. A few tests were also carried out regarding the fire properties of the PLA/PMMA blend [45,46]. However, to the best of our knowledge, the effect of ageing on flame retardancy of this flame-retarded blend has not been investigated.

In this work, flame-retarded materials have been aged in water. Three polymeric matrices were tested: pure PLA, pure PMMA, and a PLA/PMMA blend with a 50/50 wt ratio. Flame retardant systems combining a phosphorus compound and a mineral nanoparticle (sepiolite) were incorporated in these polymer and blends. The impact of ageing was observed on physico-chemical, morphological and fire properties.

\section{Experimental}

\subsection{Materials}

PLA was supplied by NatureWorks (Ingeo $3251 \mathrm{D}, \approx 1.4 \%$ D-isomer). PMMA was supplied by Arkema (Altuglas V825T). Ammonium Polyphosphate was given by Clariant (Exolit AP 423, particle size $\approx 9 \mu \mathrm{m}$, specific surface area $1.1 \mathrm{~m}^{2} / \mathrm{g}$ ). Sepiolite, a natural nanometric phyllosilicate $\left(\mathrm{Mg}_{4} \mathrm{Si}_{6} \mathrm{O}_{15}(\mathrm{OH})_{2} \cdot 6 \mathrm{H}_{2} \mathrm{O}\right.$, specific surface area $=320 \mathrm{~g} / \mathrm{m}^{2}$ ) produced by Tolsa (Pangel S9) was supplied by Lavollée S.A.

\subsection{Sample preparation}

Flame-retarded polymers (FR polymers) were compounded and pelletized using a twin screw extruder (Clextral BC 21, France) with following parameters: $\mathrm{L}=1200 \mathrm{~mm}, \quad \mathrm{~L} / \mathrm{D}=48$, screw speed $=200 \mathrm{rpm}$, melt zone temperature $=190-240^{\circ} \mathrm{C}$. For all formulations, $15 \mathrm{wt} \%$ fillers were added. Neat polymers as well as neat PLA/PMMA blend were also prepared. Formulations are listed in Table 1 . Polymers and fillers were dried in vacuum at $80^{\circ} \mathrm{C}\left(60^{\circ} \mathrm{C}\right.$ for PLA) for at least $4 \mathrm{~h}$ before melt mixing. Specimens adapted for cone calorimeter tests $\left(100 \times 100 \times 4 \mathrm{~mm}^{3}\right)$ were injection molded from the obtained pellets, after vacuum drying at $80^{\circ} \mathrm{C}$ for at least $4 \mathrm{~h}$. All samples required for analysis were cut from these square sheets.
Table 1

Name and composition of the samples prepared in this study.

\begin{tabular}{lllll}
\hline Sample code & PMMA (wt\%) & PLA (wt\%) & APP (wt\%) & Sepiolite (wt\%) \\
\hline Neat PMMA & 100 & 0 & 0 & 0 \\
Neat PLA & 0 & 100 & 0 & 0 \\
Neat blend & 50 & 50 & 0 & 0 \\
FR PMMA & 85 & 0 & 10 & 5 \\
FR PLA & 0 & 85 & 10 & 5 \\
FR blend & 42.5 & 42.5 & 10 & 5 \\
\hline
\end{tabular}

\subsection{Accelerated ageing method}

Accelerated ageing on square sheet samples were carried out using an autoclave under ambient pressure, at $100 \%$ relative humidity (RH), $70^{\circ} \mathrm{C}$, for 1,2 and 3 weeks (Fig. 1). 9 samples were completely immersed into distilled water $(8 \mathrm{~L})$. After 1 week of ageing, 3 samples were removed from the ageing media. Distilled water was then renewed into the autoclave with the last 6 samples. The same procedure was applied after the second and the third week.

\subsection{Weight variations measurements}

All the initial sample masses $m_{0}$ were measured, prior to ageing. When samples were removed from the autoclave, water was firstly wiped off from the surface, and then sample masses $m_{\text {wo }}$ were quickly measured. Finally, samples were weighed after vacuum drying at $58^{\circ} \mathrm{C}$ for $4 \mathrm{~h}$ to determine $\mathrm{m}_{\text {dry. }}$. The weight gain $\mathrm{W}_{\mathrm{g}}(\%)$ and water uptake $\mathrm{W}_{\text {up }}(\%)$ were determined following equations (1) and (2), respectively.

$$
\begin{aligned}
& \mathrm{w}_{\mathrm{g}}=\frac{\mathrm{m}_{\mathrm{dry}}-\mathrm{m}_{0}}{\mathrm{~m}_{0}} \times 100 \\
& \mathrm{~W}_{\mathrm{up}}=\frac{\mathrm{m}_{\mathrm{wo}}-\mathrm{m}_{\mathrm{dry}}}{\mathrm{m}_{\mathrm{wo}}} \times 100
\end{aligned}
$$

\subsection{Characterizations}

\subsubsection{Thermo-gravimetric analysis (TGA)}

TGA was performed on a Setaram Labsys Evo (France) apparatus. The same procedure was applied for all experiments: samples of about $20 \mathrm{mg}$ were placed into alumina crucibles, and submitted to a temperature ranging from 35 to $1000^{\circ} \mathrm{C}$, at a heating rate of $10^{\circ} \mathrm{C} /$
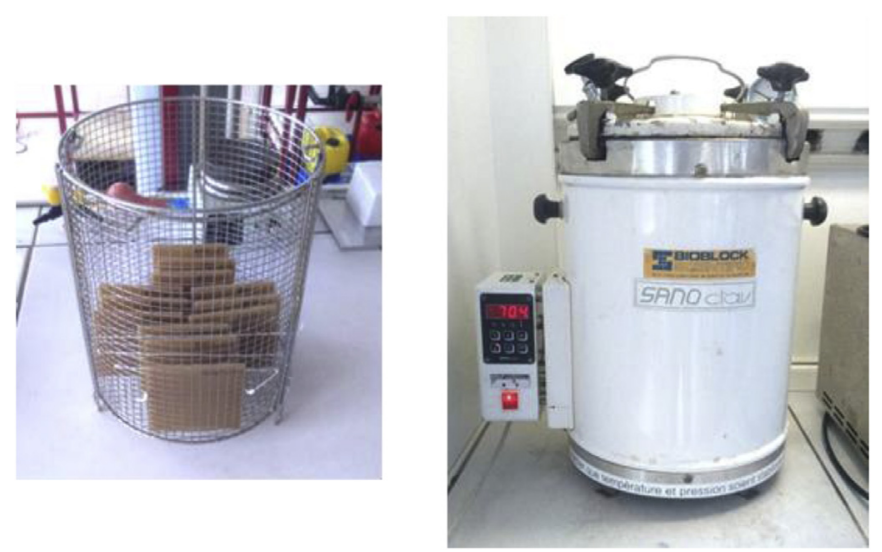

Fig. 1. Autoclave used for ageing tests. 
min, under a nitrogen flow of $50 \mathrm{~mL} / \mathrm{min}$. Unaged and aged samples were tested.

\subsubsection{Differential scanning calorimetry (DSC)}

Thermal analyses were carried out on a DSC Netzsch 200 F3 Maia, Germany. Samples of around $5 \mathrm{mg}$ were sealed in aluminium pan. They were heated up to $200^{\circ} \mathrm{C}$ with a scan rate of $10^{\circ} \mathrm{C} / \mathrm{min}$, under nitrogen flow ( $50 \mathrm{~mL} / \mathrm{min}$ ). Since PMMA is amorphous, the crystallization phenomenon observed was assigned to PLA. Considering that PMMA cannot be responsible for mass loss during ageing (as proved in the following), the crystallinity of PLA was calculated using the following equation:

$\chi_{\mathrm{c}}=\frac{\Delta \mathrm{H}_{\mathrm{m}}-\Delta \mathrm{H}_{\mathrm{cc}}}{\Delta \mathrm{H}_{\mathrm{m}}^{0}} \times \frac{100}{\mathrm{~W}_{\mathrm{PLA}}}$

where $\Delta \mathrm{H}_{\mathrm{m}}$ and $\Delta \mathrm{H}_{\mathrm{cc}}(\mathrm{J} / \mathrm{g})$ are respectively the measured melting and cold crystallization enthalpy, $\Delta \mathrm{H}_{\mathrm{m}}^{0}(\mathrm{~J} / \mathrm{g})$ is the melting enthalpy of this component in its complete crystalline state (93 J/g [47]), and $w_{P L A}$ is the weight fraction of PLA.

\subsubsection{X-Ray diffraction (XRD)}

$X$-Ray Diffraction spectra were obtained using a D8 Advance diffractometer (Bruker, EU) equipped with a $\mathrm{CuK} \alpha(\lambda=1.5406 \AA)$ source, operating at $40 \mathrm{kV}$ and $40 \mathrm{~mA}$ within a scan range of $2 \theta=2.5^{\circ}-40^{\circ}$ by steps of $0.01^{\circ}$.

\subsubsection{Hardness testing}

Shore $\mathrm{D}$ hardness testing was carried out before and after ageing using a Shore D hardness durometer model TI-D (Sauter GmbH, Germany). 7 points were taken for each measurement.

\subsubsection{Inductively coupled plasma atoms emission spectroscopy (ICP-AES)}

ICP-AES analyses (HORIBA Jobin Yvon, Activa M) were performed to determine the phosphorus content into the sample before and after ageing. Samples were dissolved in an acid solution (nitric/sulfuric acid).

\subsubsection{Viscosity}

Melt viscosity were measured with a rotational rheometer (Anton Paar MCR-301, Germany), using a PP-25 measuring system with a gap of $1 \mathrm{~mm}$. Tests were conducted at $200^{\circ} \mathrm{C}$, and the range of shear rate from 0.1 to $600 \mathrm{~s}^{-1}$ was applied.

\subsubsection{Gel permeation chromatography (GPC)}

The molar mass $\mathrm{M}_{\mathrm{W}}$ and polydispersity index PD of unaged and aged samples were determined using gel permeation chromatography (Varian ProStar model 210, US) equipped with a RI detector. Two PLgel $5 \mu \mathrm{m}$ Resipore were used at $70^{\circ} \mathrm{C}$, calibrated with PMMA standards. Samples were initially dissolved in DMF $(10 \mathrm{mg} / \mathrm{ml})$ and then eluted. The measurements were carried out with a constant flow rate of $0.8 \mathrm{ml} / \mathrm{min}$.

\subsubsection{Scanning electron microscopy (SEM)}

The internal structure of the sheets before and after ageing was examined using an environmental scanning electron microscope (SEM) (FEI Quanta 200, The Netherlands). A small sample was obtained by cutting a part of the sheet, before cryo-fracturing and then coated with a thin carbon layer. Observations were carried out under high vacuum at $3 \mathrm{kV}$, with a working distance of $10 \mathrm{~mm}$ and a spot size of 3-4 $\mu \mathrm{m}$. The phosphorus content was determined using energy dispersive X-ray (EDX) spectroscopy.

\subsubsection{Fire testing}

The flammability properties of formulations were evaluated using a cone calorimeter device (FTT, UK and Fire, EU according to the ISO 5660-1 standard). All samples were dried under vacuum during at least $6 \mathrm{~h}$ before experiments. Sheets of $100 \times 100 \times 4 \mathrm{~mm}^{3}$ were exposed to a radiant cone with a heat flux of $50 \mathrm{~kW} / \mathrm{m}^{2}$. The samples were all evaluated in horizontal orientation and ignited using a spark igniter. Each experiment was repeated at least twice. Time to ignition (TTI), heat release rate (HRR), total heat release (THR), peak of heat release rate (pHRR), residue at flame out and effective heat of combustion (EHC) were recorded.

\section{Results and discussion}

\subsection{Miscibility of the PLA/PMMA blend}

DSC curves for extruded unfilled polymers are shown in Fig. 2. The glass transition temperature $\mathrm{T}_{\mathrm{g}}$, cold crystallization temperature $\mathrm{T}_{\mathrm{cc}}$, enthalpy $\Delta \mathrm{H}_{\mathrm{cc}}$, melting temperature $\mathrm{T}_{\mathrm{m}}$, and enthalpy $\Delta \mathrm{H}_{\mathrm{m}}$, as well as calculated PLA cristallinity, are summarized in Table 2. Neat PMMA and PLA show a glass transition temperature $\left(T_{g}\right)$ at $117^{\circ} \mathrm{C}$ and $61{ }^{\circ} \mathrm{C}$, respectively. Two other transitions are visible at $99^{\circ} \mathrm{C}$ and $173^{\circ} \mathrm{C}$, corresponding respectively to the well-known cold crystallization of PLA and the melting of its crystalline part All these results are in accordance with the literature [48].

During the first heating scan, two glass transitions appeared for PLA/PMMA 50/50 blends, related to both polymers (see Fig. 3). But these temperatures are different from that of neat polymers. They
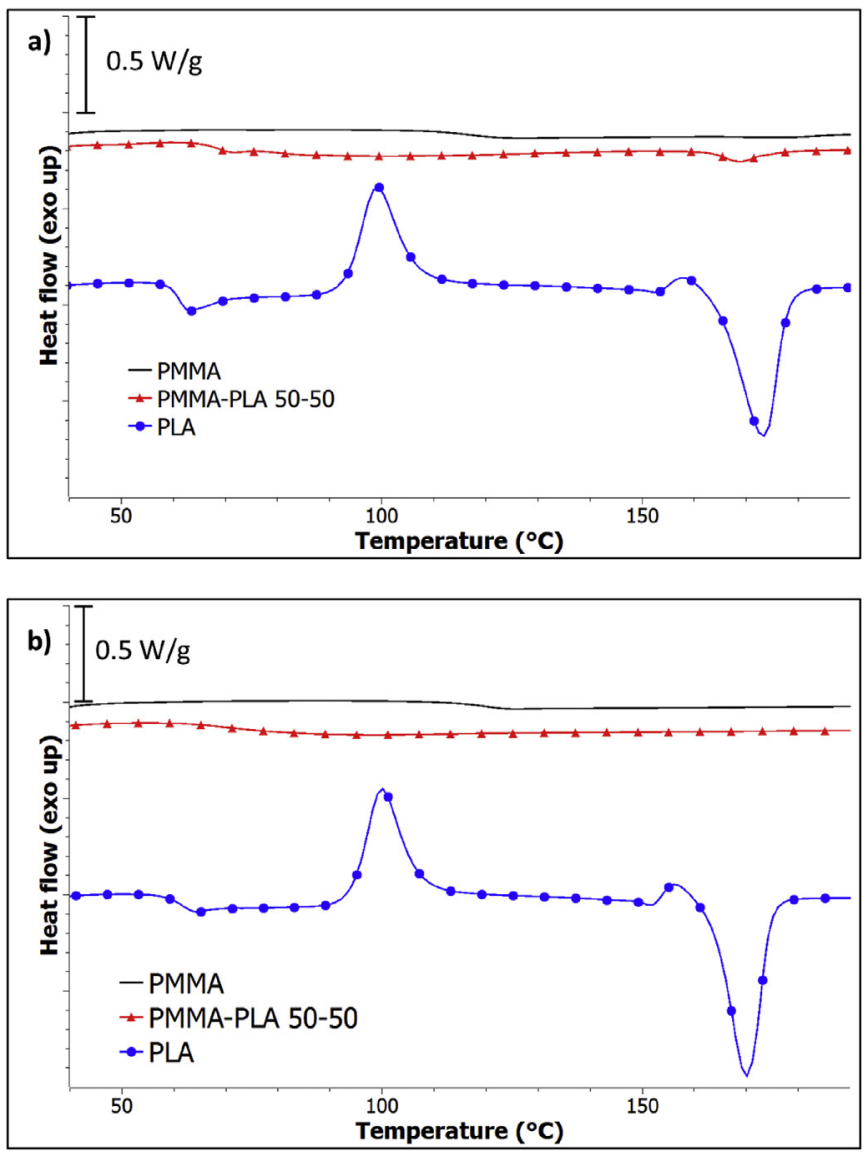

Fig. 2. DSC first (a) and second (b) heating scan thermograms of unfilled polymers. 
Table 2

DSC main values ( $\mathrm{T}_{\mathrm{g}}, \mathrm{T}_{\mathrm{cc}}, \mathrm{T}_{\mathrm{m}}$ : transition temperatures, $\Delta \mathrm{H}_{\mathrm{cc}}, \Delta \mathrm{H}_{\mathrm{m}}$ : cold crystallization and melting enthalpies, $\chi_{\mathrm{c}}$ : PLA crystallinity).

\begin{tabular}{|c|c|c|c|c|c|c|c|}
\hline Formulation & Heating & $\mathrm{T}_{\mathrm{g}}\left({ }^{\circ} \mathrm{C}\right)$ & $\mathrm{T}_{\mathrm{cc}}\left({ }^{\circ} \mathrm{C}\right)$ & $\Delta \mathrm{H}_{\mathrm{cc}}(\mathrm{J} / \mathrm{g})$ & $\mathrm{T}_{\mathrm{m}}\left({ }^{\circ} \mathrm{C}\right)$ & $\Delta \mathrm{H}_{\mathrm{m}}(\mathrm{J} / \mathrm{g})$ & $\chi_{\mathrm{c}}(\%)$ \\
\hline \multirow[t]{2}{*}{ PMMA } & First & 117 & - & 0 & - & 0 & 0 \\
\hline & Second & 121 & - & 0 & - & 0 & 0 \\
\hline \multirow[t]{2}{*}{ PLA/PMMA 50/50 } & First & $81-68$ & - & 0 & 169 & 3 & 5 \\
\hline & Second & 72 & - & 0 & - & 0 & 0 \\
\hline \multirow[t]{2}{*}{ PLA } & First & 61 & 99 & $28 \pm 2$ & 173 & $45 \pm 3$ & $18 \pm 2$ \\
\hline & Second & 61 & 100 & $28 \pm 2$ & 170 & $44 \pm 3$ & $17 \pm 2$ \\
\hline
\end{tabular}

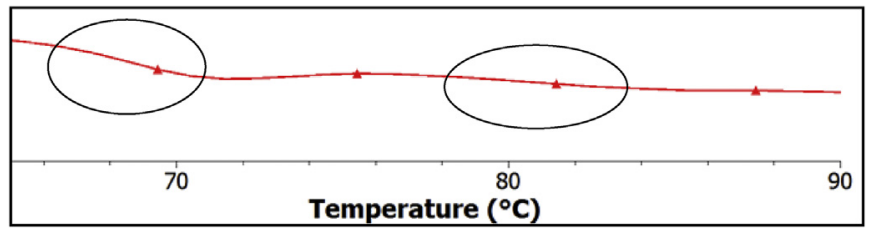

Fig. 3. Zoom on the unfilled extruded PLA/PMMA blend first heating scan thermogram.

reveal the partial miscibility of the blend leading to the presence of two bi-component (non pure) phases.

During the second scan, when the thermal history of the blend was removed, a single glass transition was observed at $72{ }^{\circ} \mathrm{C}$. Therefore, it can be concluded that the mixture become completely miscible.

Another result concerns the semi-crystalline behaviour of PLA. A melting peak appeared during the first scan for pure PLA and PLA/ PMMA blend. The associated crystallinities of PLA were respectively $18 \%$ and $5 \%$. These crystalline fractions appeared during the processing of the blend. The very low crystallinity observed in the blend clearly indicates that the addition of PMMA inhibited the crystallization of PLA.

During the second scan, cold crystallization of pure PLA still occurred: the same crystallinity was measured for pure PLA. But differences appeared between first and second scan for PLA/PMMA blend, for which no crystallinity was observed. These results showed the ability of PMMA to reduce the crystallization phenomenon of PLA. PMMA has a higher $\mathrm{T}_{\mathrm{g}}$, meaning a lower mobility of macromolecules, that induced in turn a restriction in mobility of PLA chains: PMMA slows down the crystallization kinetics of PLA. Other studies noticed the same phenomenon [27,49-51], that confirms interactions occurring between PMMA and PLA.

The present study revealed that initial extrusion process of the unfilled blend did not lead to a complete miscibility; but a thermal treatment corresponding to an annealing process could confer the total miscibility of the blend.

Flame-retarded PLA/PMMA blends were also investigated. Such specimens have been firstly extruded, and then processed by injection molding. Thermal properties of unfilled and FR blends have been studied by DSC (Fig. 4).

Results showed only $1 \mathrm{~T}_{\mathrm{g}}$ for the blends, at $68^{\circ} \mathrm{C}$ : the injection process conferred total miscibility. SEM picture (Fig. 5) of flameretarded formulation showed that a good dispersion of the phosphorous and sepiolite particles was obtained.

\subsection{Impact of ageing on morphological characteristics}

Table 3 shows the mass variations of neat polymers, and flameretarded samples after ageing.

Neat PMMA showed a slight increase in its mass during ageing even after drying the samples, whereas water uptake was stable. This indicates that a small amount of water has been absorbed by

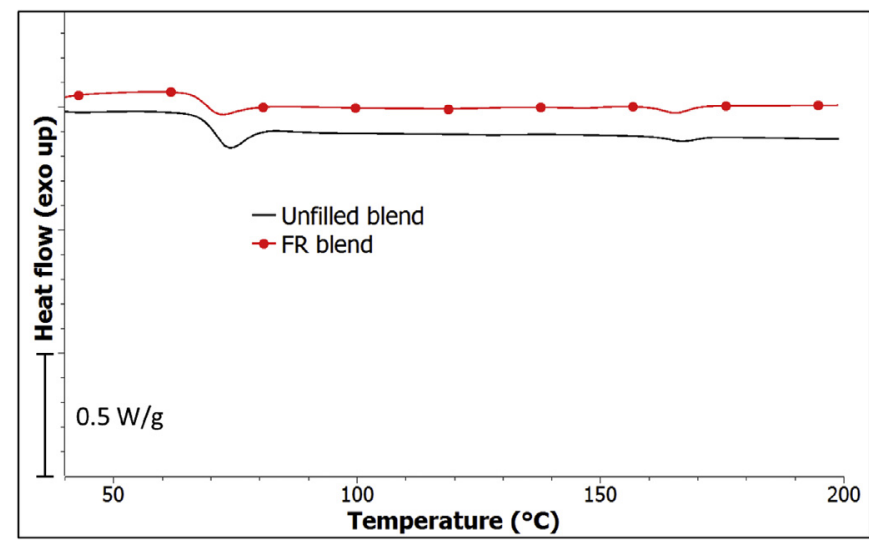

Fig. 4. DSC of the samples prepared by extrusion/injection process (first heating scan).

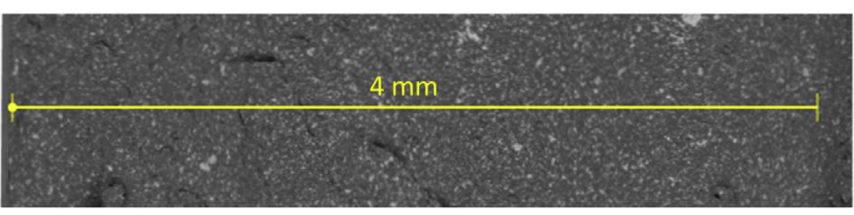

Fig. 5. SEM picture of the flame-retarded blend.

the sheets, and even after drying under vacuum, a part of this water is trapped in the sample. Consequently, the water uptakes calculated are approximations, and only give us an indication of the behaviour of the materials. At the same time, flame-retarded PMMA sample masses increased with ageing time, from $5 \%$ to $9 \%$ from 1 to 3 weeks.

Conversely, neat PLA has lost an important part of its initial mass after ageing; that loss increased with the ageing time, from $7 \%$ to $26 \%$ after one week and three weeks of ageing, respectively. At the same time, water uptake increased from $7 \%$ to $23 \%$. This result indicates hydrolysis phenomena occurred, and a part of the polymer was decomposed into small oligomers and dissolved into the ageing media. In the case of flame-retarded PLA, the masses decreased from $13 \%$ to $34 \%$ after 3 weeks of ageing, with a water uptake increasing from $11 \%$ to $29 \%$. The more important weight losses observed when fillers are added are due to the dissolution of a part of flame retardant compound (APP) in the aqueous ageing media as evidenced in the following.

The weight of unfilled blend increased with ageing time, from $1 \%$ to $5 \%$, as well as the water uptake that increased from $0.5 \%$ to $4.5 \%$. In order to check if a mixing rule occurred, comparison of these results was done with values obtained with eq. (4) for any ageing time. Results shown on Fig. 6 (a) did not evidence mixing rule.

$W_{g \text { calc. }}=0.5 \times W_{g \exp P M M A}+0.5 \times W_{g \exp P L A}$. 
Table 3

Impact of ageing on sample masses.

\begin{tabular}{|c|c|c|c|}
\hline Formulations & Ageing time (week) & Weight gain $\mathrm{W}_{\mathrm{g}}(\%)$ & Water uptake $\mathrm{W}_{\text {up }}(\%)$ \\
\hline \multirow[t]{3}{*}{ Neat PMMA } & 1 & $1.1 \pm 0.1$ & $0.5 \pm 0.1$ \\
\hline & 2 & $1.4 \pm 0.1$ & $0.3 \pm 0.1$ \\
\hline & 3 & $1.4 \pm 0.1$ & $0.4 \pm 0.1$ \\
\hline \multirow[t]{3}{*}{ Neat PLA } & 1 & $-7.1 \pm 0.1$ & $7.3 \pm 0.4$ \\
\hline & 2 & $-18.5 \pm 0.1$ & $16.4 \pm 0.6$ \\
\hline & 3 & $-26.0 \pm 0.1$ & $22.7 \pm 0.6$ \\
\hline \multirow[t]{3}{*}{ Neat blend } & 1 & $1.0 \pm 0.1$ & $0.5 \pm 0.1$ \\
\hline & 2 & $2.5 \pm 0.1$ & $1.3 \pm 0.1$ \\
\hline & 3 & $5.4 \pm 0.4$ & $4.5 \pm 0.2$ \\
\hline \multirow[t]{3}{*}{ FR PMMA } & 1 & $4.9 \pm 0.1$ & $1.2 \pm 0.1$ \\
\hline & 2 & $7.4 \pm 0.1$ & $1.2 \pm 0.1$ \\
\hline & 3 & $8.9 \pm 0.1$ & $1.2 \pm 0.1$ \\
\hline \multirow[t]{3}{*}{ FR PLA } & 1 & $-12.9 \pm 0.1$ & $11.1 \pm 0.2$ \\
\hline & 2 & $-25.8 \pm 0.3$ & $20.9 \pm 0.2$ \\
\hline & 3 & $-33.6 \pm 0.7$ & $28.6 \pm 0.6$ \\
\hline \multirow[t]{3}{*}{ FR blend } & 1 & $8.9 \pm 0.3$ & $9.3 \pm 0.2$ \\
\hline & 2 & $11.3 \pm 0.2$ & $9.9 \pm 0.1$ \\
\hline & 3 & $8.3 \pm 0.6$ & $11.1 \pm 0.5$ \\
\hline
\end{tabular}

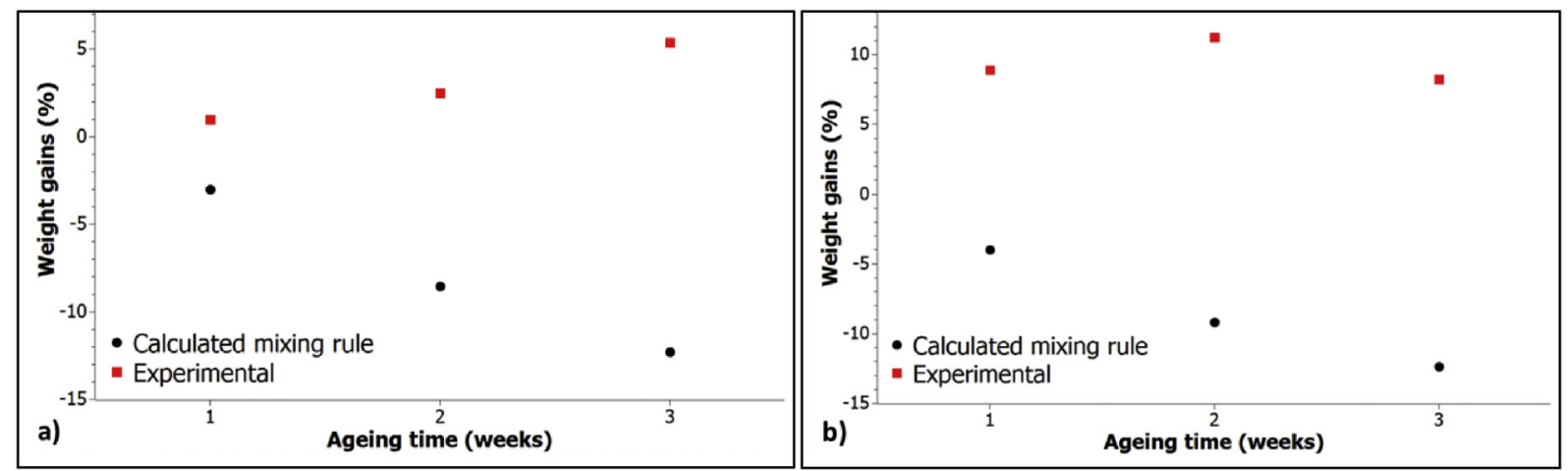

Fig. 6. Weight gain - comparison between linear mixing rule prevision and experimental results for unfilled (a) and flame-retarded blend (b).

Flame-retarded blend showed intermediate water uptakes, which increased with ageing time from $9 \%$ to $11 \%$. But the weight gains were surprising: on the one hand, they were more important than flame-retarded PMMA, and it is clear that they did not follow any mixing rule calculated from the values observed for flameretarded PMMA and flame-retarded PLA (Fig. 6 (b)). On the other hand, they firstly increased from $9 \%$ to $11 \%$ between the first two weeks, and then decreased at $8 \%$ after three weeks. This probably means that PLA allows water to penetrate more easily in the materials, and once water is inside the sample, PMMA blocks the evacuation of the shortened PLA chains during drying.

These mass variations revealed that a competition occurs between several phenomena during ageing (Fig. 7). On the one hand, incorporation of fillers creates weak interfacial interactions, allowing water to penetrate more easily into the sample. When PLA is a part of the polymeric matrix, water can also easily penetrate

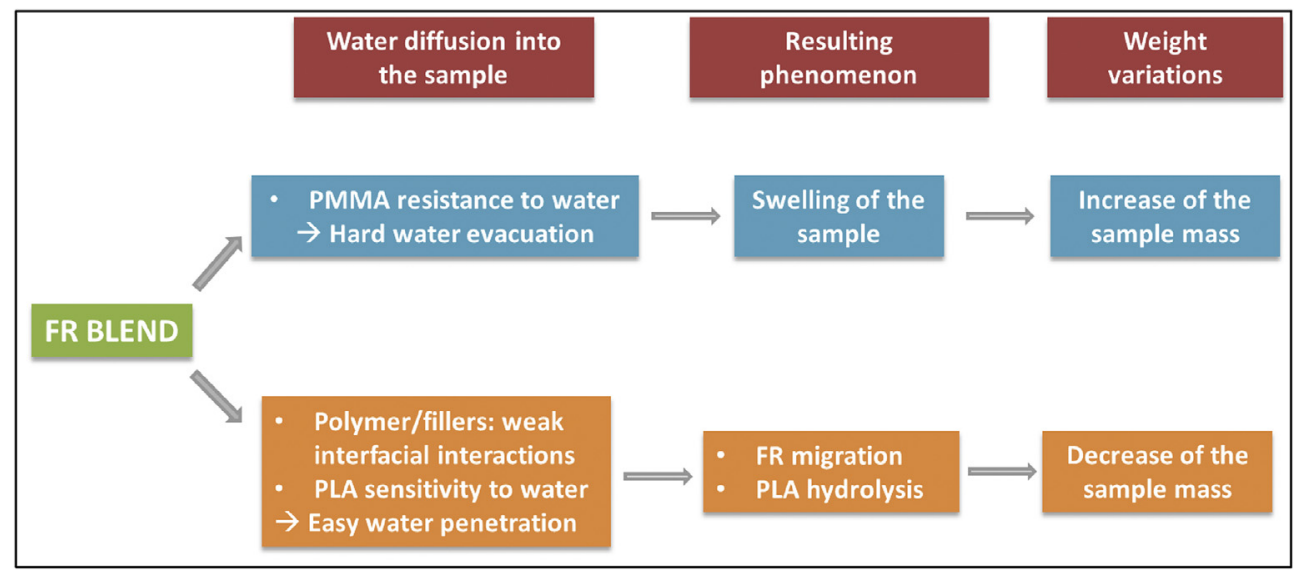

Fig. 7. Competition between various phenomena during ageing. 
a)

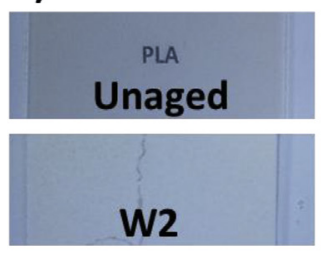

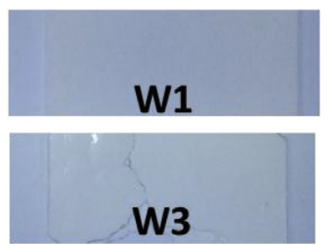

b)

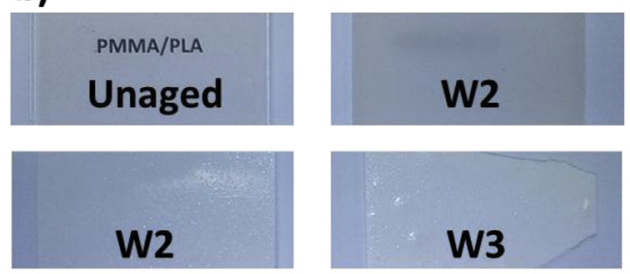

c)
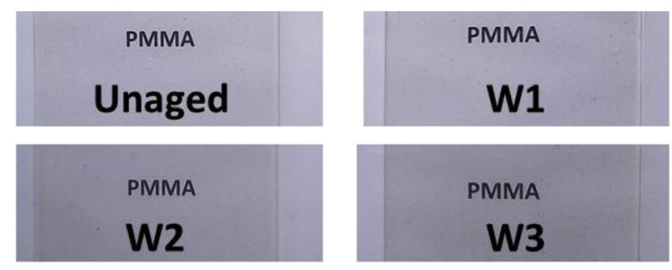

Fig. 8. Visual appearance of neat PLA (a), neat blend (b) and neat PMMA (c) before and after ageing (W1, W2 and W3 for samples aged for 1, 2 and 3 weeks respectively).

into the composite. These two phenomena lead to a swelling and an increase of the sample mass. On the other hand, PLA hydrolysis as well as migration of flame retardants facilitated by the swelling induces mass loss.

Visual modifications appeared after ageing. Concerning neat PLA and PLA/PMMA blend, ageing induced whitening and an opacity of the sheets. As can be seen on Fig. 8, the name of the polymeric matrix written on a paper under the samples was not visible after one week of ageing for PLA specimens. Concerning PLA/PMMA blend, one can notice something was written after one week of ageing, but nothing appeared after two weeks of ageing.

This opacity may be explained by the crystallization of PLA during ageing [22,51]. To confirm this hypothesis, XRD analyses were done (Fig. 9 a)).

Unaged PLA did not exhibit any diffraction peak, whereas after ageing peaks appeared at $2 \theta$ values of $14.9,16.7,19.1$ and $22.5^{\circ}$
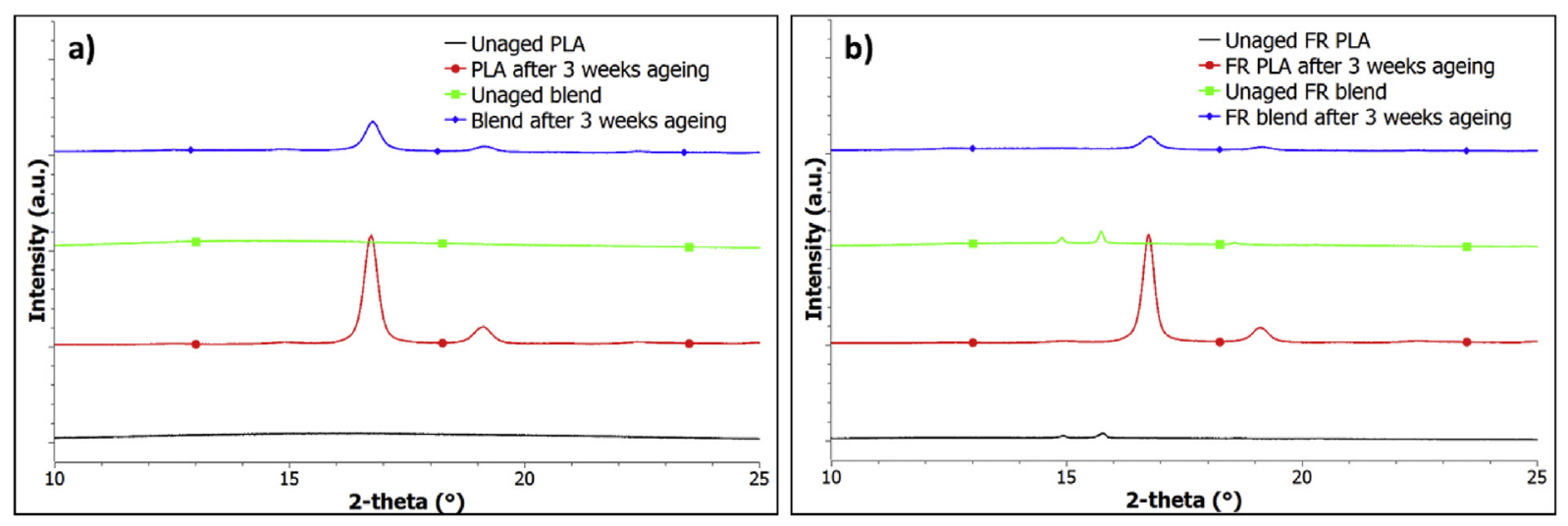

Fig. 9. XRD patterns of unfilled polymers (a) and flame-retarded polymers (b).
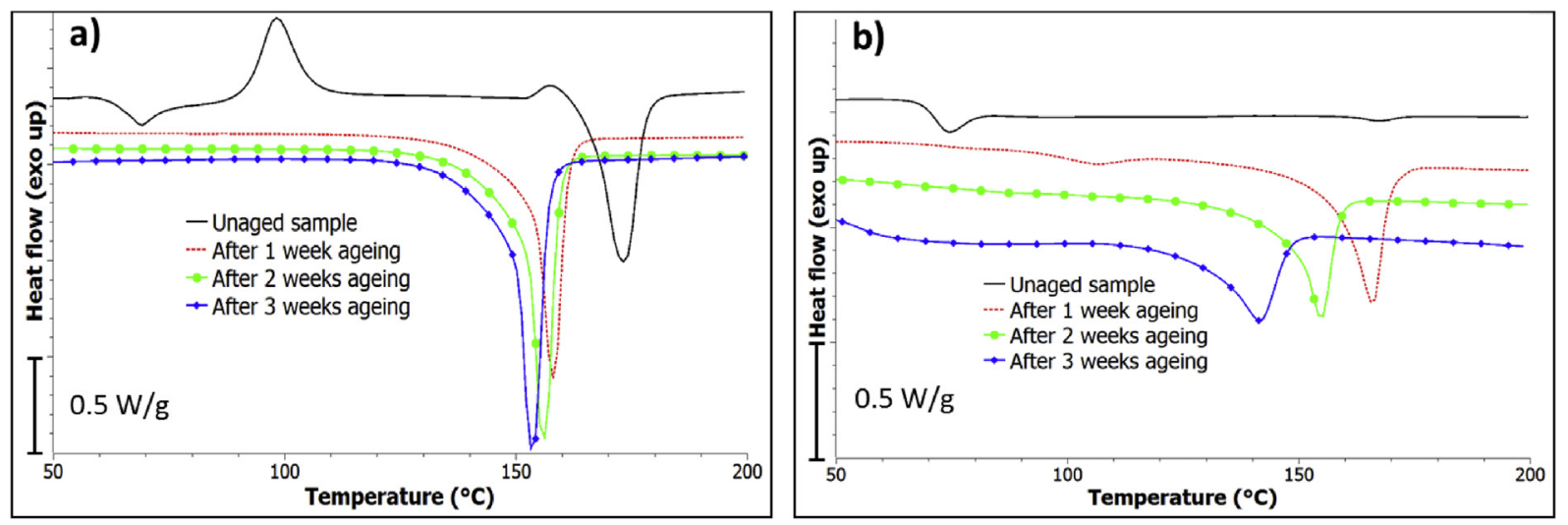

Fig. 10. DSC first heating scan of neat PLA (a) and PLA/PMMA (b) unfilled blend before and after ageing. 
Table 4

Main DSC results of unfilled materials.

\begin{tabular}{|c|c|c|c|c|c|}
\hline Polymer & Ageing time & Melting temperature $\mathrm{T}_{\mathrm{m}}\left({ }^{\circ} \mathrm{C}\right)$ & Melting enthalpy $\Delta \mathrm{H}_{\mathrm{m}}(\mathrm{J} / \mathrm{g})$ & Cold crystallization enthalpy $(\mathrm{J} / \mathrm{g})$ & $\chi_{c}(\%)$ \\
\hline \multirow[t]{4}{*}{ PLA } & Unaged & 173 & $42 \pm 5$ & $20 \pm 3$ & 23 \\
\hline & 1 week & 158 & $55 \pm 5$ & 0 & 59 \\
\hline & 2 weeks & 156 & $65 \pm 5$ & 0 & 70 \\
\hline & 3 weeks & 153 & $67 \pm 5$ & 0 & 72 \\
\hline \multirow[t]{4}{*}{ PLA/PMMA 50/50 } & Unaged & 167 & $1 \pm 0.5$ & 0 & 2 \\
\hline & 1 week & 165 & $34 \pm 3$ & 0 & - \\
\hline & 2 weeks & 155 & $33 \pm 3$ & 0 & - \\
\hline & 3 weeks & 142 & $31 \pm 3$ & 0 & - \\
\hline
\end{tabular}
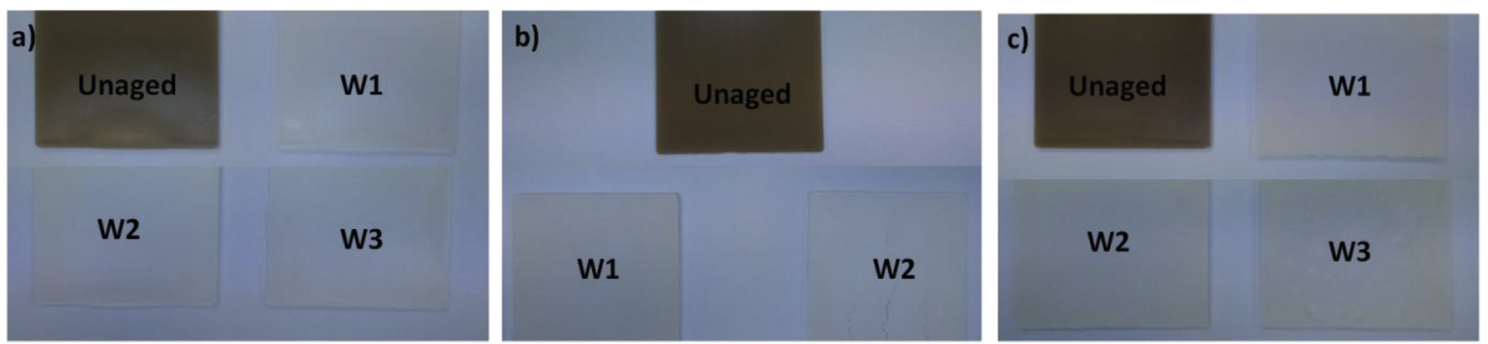

Fig. 11. Visual appearance of flame-retarded PMMA (a), flame-retarded PLA (b) and flame-retarded blend (c)

corresponding respectively to the (010) plane, (110) and/or (200) plane, (203) plane and (210) plane of orthorhombic PLA crystals [28,52-55]. The same observations were done with PLA/PMMA blend, showing ageing induced crystallization of PLA. DSC was also performed (Fig. 10), main results are in Table 4. Because of the various phenomena happening during ageing of the blend (water absorption and oligomers removal after PLA hydrolysis), it was not possible to determine the exact PLA amount in the blend; hence crystallization rate of the blend after ageing has not been calculated, only melting enthalpy are presented.

Firstly, in both neat PLA and PLA/PMMA blend, the melting temperatures decreased with ageing time: PLA chains became

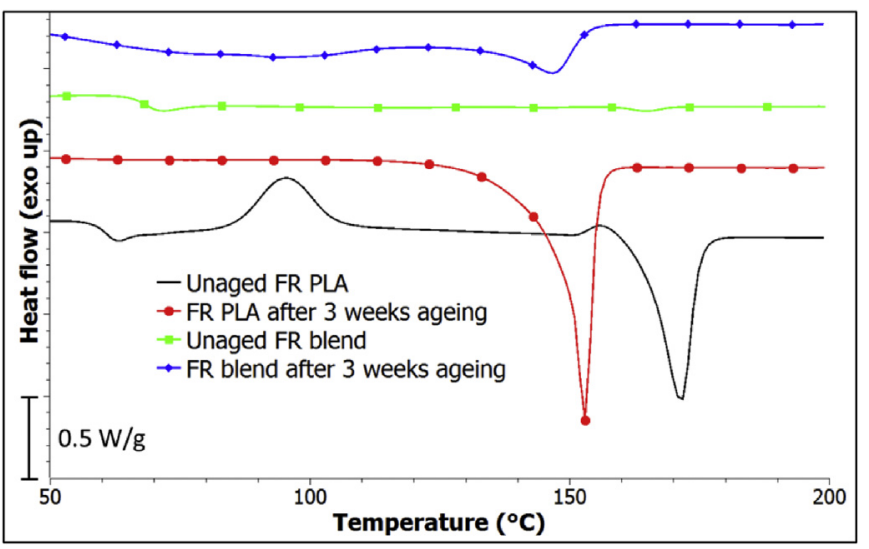

Fig. 12. DSC first heating scan of FR materials before and after ageing. shorter due to hydrolysis. This decrease of chain length is responsible for the decreased melting temperatures. Cold crystallization phenomenon appeared at around $100^{\circ} \mathrm{C}$ for unaged neat PLA; then it was not observed after ageing. That means ageing induced more complete crystallization of the PLA and no more chains are able to crystallize during heating. Variations of melting enthalpy were also observed. During ageing, PMMA remains intact in the composite, contrary to PLA which undergoes hydrolysis and dissolution of oligomers. Unaged blend had a very low melting enthalpy: the sample had almost no crystallinity. The enthalpy increased drastically after 1 week of ageing: the high temperature in the aqueous media combined with the higher chain mobility due to hydrolysis and plasticizing effect of water induced crystallization of PLA fraction into the composite (further crystallization during ageing is also observed for pure PLA). This enthalpy remained almost stable after supplementary ageing time, revealing PLA crystallization into the blend reached its maximum during the first ageing week.

Flame-retarded materials also exhibit whitening during ageing, as can be seen in Fig. 11. Surprisingly, this whitening also appeared for flame-retarded PMMA, which does not exhibit crystallization. Migration phenomena may explain this whitening. Jimenez and al [33]. Have shown modifications occurred when APP was in presence of water, leading to formation of phosphoric acid. It has been shown that this phosphoric acid can migrate towards the sample surface during ageing [39], explaining the whitening.

Crystallinity of flame-retarded materials was evaluated by XRD (Fig. 9 b) and DSC analyses (Fig. 12, Table 5). Because of various phenomena occurring during ageing (PMMA water absorption, PLA hydrolysis, phosphorus loss), crystallization rate of aged sample has not been calculated.

Table 5

Melting characteristics of flame-retarded composite.

\begin{tabular}{|c|c|c|c|c|c|}
\hline Polymer & Ageing time & Melting temperature $\mathrm{T}_{\mathrm{m}}\left({ }^{\circ} \mathrm{C}\right)$ & Melting enthalpy $\Delta \mathrm{H}_{\mathrm{m}}(\mathrm{J} / \mathrm{g})$ & Cold crystallization enthalpy $\Delta \mathrm{H}_{\mathrm{cc}}(\mathrm{J} / \mathrm{g})$ & $\chi_{c}(\%)$ \\
\hline \multirow[t]{2}{*}{ FR PLA } & Unaged & 172 & $44 \pm 5$ & $23 \pm 3$ & 26 \\
\hline & 3 weeks & 153 & $66 \pm 5$ & 0 & - \\
\hline \multirow[t]{2}{*}{ FR blend } & Unaged & 165 & $1 \pm 0.5$ & 0 & 3 \\
\hline & 3 weeks & 147 & $15 \pm 2$ & 0 & - \\
\hline
\end{tabular}


XRD patterns of unaged samples showed two diffraction peaks at $2 \theta$ values of 14.9 and $15.7^{\circ}$, due to the orthorhombic structure of APP [56,57]. No diffraction peak corresponding to PLA crystals was visible. After ageing, for both FR PLA and FR blend, two main diffraction peaks appeared at $2 \theta$ values of 16.7 and $19.1^{\circ}$, characteristics of PLA crystals. These peaks revealed that PLA crystallized during ageing. DSC revealed an increase of the melting enthalpy after ageing, confirming that crystallization.

Regarding flame-retarded PLA, a clear loss in mechanical properties was observed as ageing time increased, due to hydrolysis. The resulting materials became very brittle, as shown on Table 6: after 3 weeks of ageing, the hardness of PLA-based formulation was drastically reduced, from 84 to 35 . This loss was less pronounced in the case of flame-retarded blend, and was not significant for flameretarded PMMA.

After ageing, a modification of sample size was observed for flame-retarded PLA and flame-retarded blend (Fig. 13, Table 7). The former exhibited a smaller size after ageing, whereas the latter get larger dimensions, confirming the hypothesis of water absorption. No modification occurred concerning flame-retarded PMMA.

\subsection{Impact of ageing on the thermo-mechanical properties}

\subsubsection{Rheological profiles}

Viscosity measurements were performed on composite specimens before and after ageing ( 3 weeks). Results are shown on Fig. 14 and Fig. 15.

Concerning flame-retarded PMMA, the viscosity of unaged sample is almost unchanged after 3 weeks ageing: the immersion in hot distilled water seems to have a limited impact on PMMA

Table 6

Shore D hardness of flame-retarded materials.

\begin{tabular}{lll}
\hline Materials & Hardness \\
\cline { 2 - 3 } & Unaged sample & After 3 weeks of ageing \\
\hline FR PMMA & $88 \pm 1$ & $82 \pm 2$ \\
FR PLA & $84 \pm 2$ & $35 \pm 8$ \\
FR blend & $87 \pm 2$ & $69 \pm 1$ \\
\hline
\end{tabular}

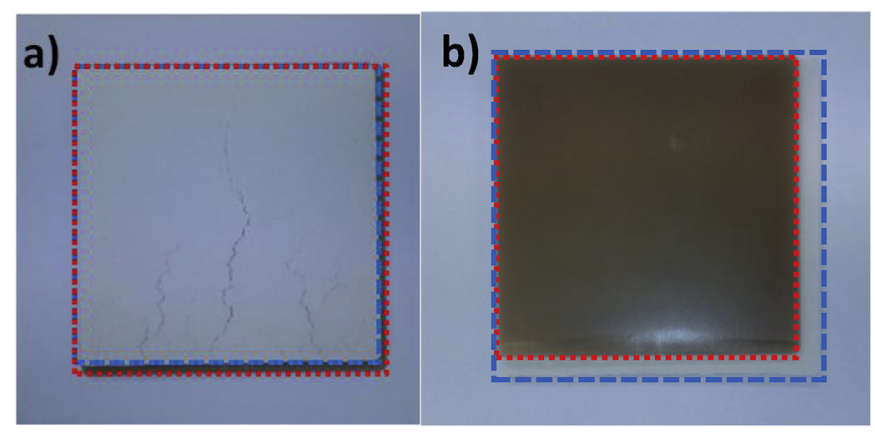

Fig. 13. Modification of the sample sizes of flame-retarded PLA (a) and flame-retarded blend (b) (red: unaged sample, blue: after 3 weeks of ageing). (For interpretation of the references to colour in this figure legend, the reader is referred to the Web version of this article.)

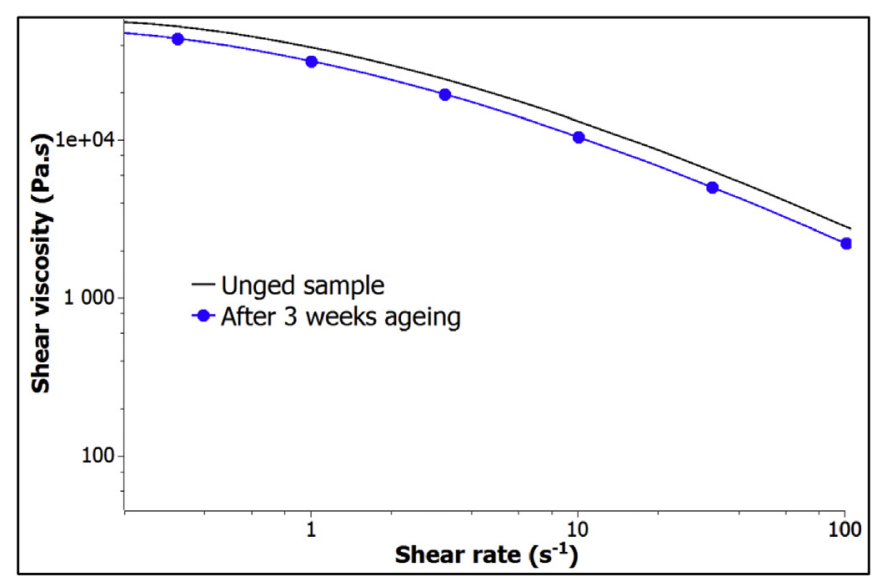

Fig. 14. Viscosity profiles of unaged and aged flame-retarded PMMA.
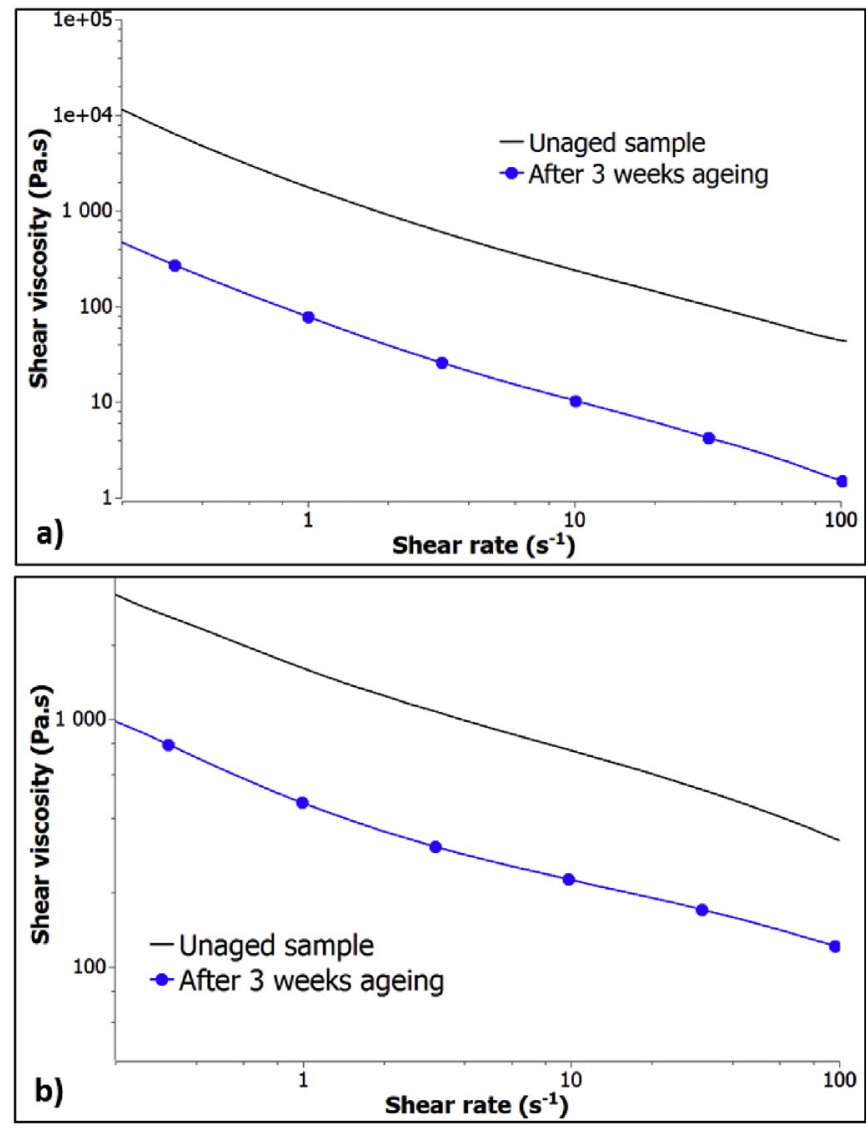

Fig. 15. Viscosity profiles of flame-retarded PLA (a) and flame-retarded blend (b).

macromolecular chains, as already evidenced by other analyses.

Results are different with flame-retarded PLA and flameretarded blend: as shown on Fig. 15, at any shear rate, the aged sample had a lower viscosity than unaged sample. This decrease

Table 7

Evolution of dimensions after ageing.

\begin{tabular}{|c|c|c|c|c|}
\hline \multirow{2}{*}{$\frac{\text { Formulations }}{\text { Ageing time }}$} & \multicolumn{2}{|c|}{ Flame-retarded PLA } & \multicolumn{2}{|c|}{ Flame-retarded blend } \\
\hline & Unaged & After ageing ( 3 weeks) & Unaged & After ageing ( 3 weeks) \\
\hline Dimensions after drying $\left(\mathrm{mm}^{3}\right)$ & $10 \times 10 \times 4$ & $9.7 \times 9.7 \times 4$ & $10 \times 10 \times 4$ & $10.7 \times 10.7 \times 4$ \\
\hline
\end{tabular}


can be explained by the hydrolysis of PLA macromolecular chains, during hydrothermal ageing.

GPC measurements were performed in order to confirm this hypothesis. Results are shown in Table 8. FR PMMA did not exhibit modifications of its molecular weight after ageing. Conversely, ageing led to a significant decrease of the molecular weight of FR PLA, from 71.9 to $3.0 \mathrm{~kg} / \mathrm{mol}$, confirming hydrolysis phenomena. Ageing of the FR blend induced a separation of the polymer population.

\subsubsection{Evolution of the phosphorus content}

Since a phosphorous compound is the main component conferring fire properties to our materials, a determination of the phosphorus content of specimens before and after ageing was performed. ICP-AES measurements were carried out in order to determine the evolution of the phosphorus concentration into the samples. EDX analyses were also performed for each sample, in

Table 8

Average molecular weight and polydispersity index (PD) of unaged and aged samples.

\begin{tabular}{llllll}
\hline Formulation & \multicolumn{2}{l}{ Unaged samples } & & \multicolumn{2}{l}{$\begin{array}{l}\text { Samples after 3 weeks of } \\
\text { ageing }\end{array}$} \\
\cline { 2 - 3 } \cline { 5 - 6 } & $\mathrm{M}_{\mathrm{w}}(\mathrm{kg} / \mathrm{mol})$ & $\mathrm{PD}$ & & $\mathrm{M}_{\mathrm{w}}(\mathrm{kg} / \mathrm{mol})$ & $\mathrm{PD}$ \\
\hline FR PMMA & 84.7 & 1.67 & & 86.9 & 1.67 \\
FR PLA & 71.9 & 1.49 & & 3.0 & 1.36 \\
FR blend & 70.4 & 1.82 & & $84.4 / 4.0$ & $1.76 / 1.52$ \\
\hline
\end{tabular}

order to compare the phosphorus gradient from the centre to the outside of the sheet (Fig. 16). Results are tabulated in Table 9.

After 3 weeks of ageing, a slight decrease in phosphorus content was observed in flame-retarded PMMA. The phosphorus concentration was the same in the centre as in the outside of the sheet (see Fig. 18 (a)).

Concerning flame-retarded PLA, the phosphorus content falls from $3.25 \%$ before ageing to $0.29 \%$ after 3 weeks of immersion. This almost complete loss of phosphorus concentration is expected to induce a degradation of fire properties. Moreover, a gradient of phosphorus concentration has been observed, with more phosphorus in the centre of the sheet $(1.5 \%)$ than in the surface $(0.8 \%)$ (Figs. 17 and 18 (b)).

These results suggest that during ageing, a large part of phosphorus flame retardants was extracted and transferred to the ageing media, especially when FRs were close to the surface, i.e. easily reachable to water. The same conclusions were recently obtained concerning HIPS composites [58]. Authors showed that during ageing, a migration of phosphorus to the surface of the samples occurred, followed by erosion mechanism.

The flame-retarded blend showed an intermediate loss of its phosphorus content, and also revealed a concentration gradient from the centre to the surface of the sheet (Fig. 18 (c)).

\subsection{Impact of ageing on thermal properties}

\subsubsection{TGA analysis}

The thermal degradation process of the unaged and 3 week-
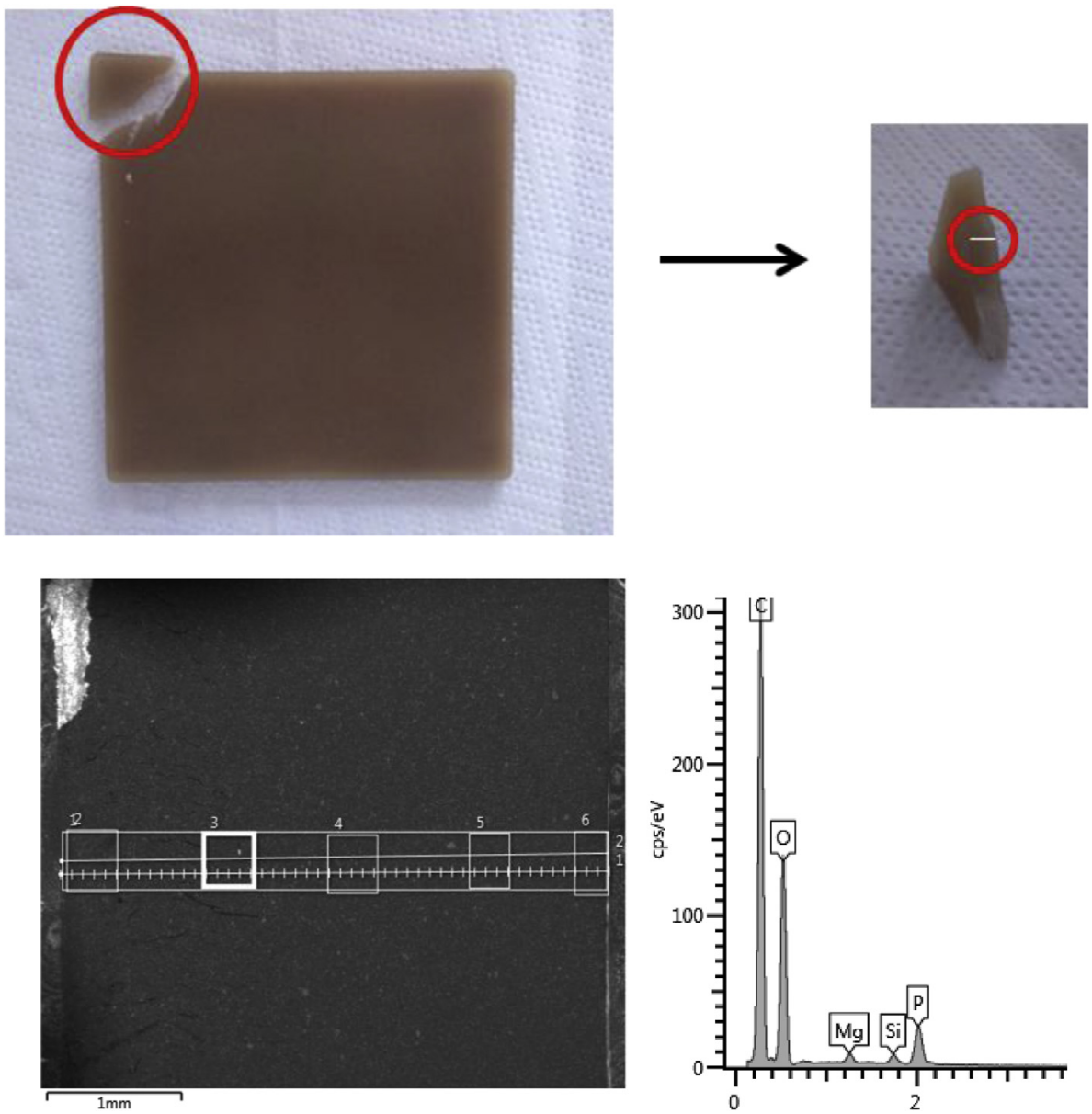

Fig. 16. EDX analyses of the unaged flame-retarded PMMA. 
Table 9

Phosphorus content determined by ICP and EDX.

\begin{tabular}{|c|c|c|c|c|c|}
\hline \multirow[t]{2}{*}{ Flame-retarded composite } & \multicolumn{3}{|c|}{ Phosphorus content (wt\%) } & \multicolumn{2}{|c|}{ Concentration gradient } \\
\hline & Unaged & After ageing ( 3 weeks) & Phosphorus loss & Unaged & After ageing ( 3 weeks) \\
\hline FR PMMA & $3.51 \% \pm 0.03$ & $3.34 \% \pm 0.01$ & $5 \%$ & No & No \\
\hline FR PLA & $3.25 \% \pm 0.07$ & $0.29 \% \pm 0.03$ & $91 \%$ & No & Yes \\
\hline FR blend & $3.30 \% \pm 0.11$ & $2.11 \% \pm 0.03$ & $36 \%$ & No & Yes \\
\hline
\end{tabular}

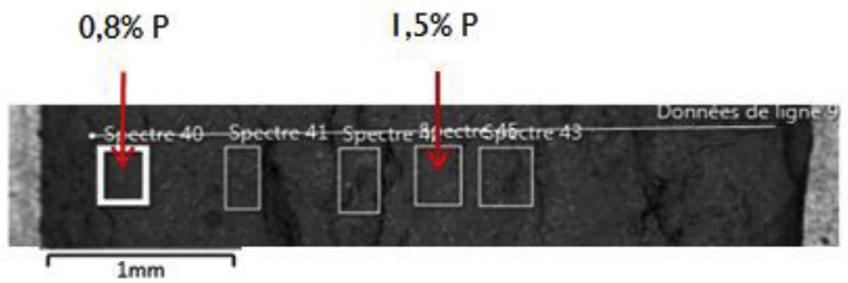

Fig. 17. Variation of phosphorus content into the plate (flame-retarded PLA after 3 weeks of ageing).
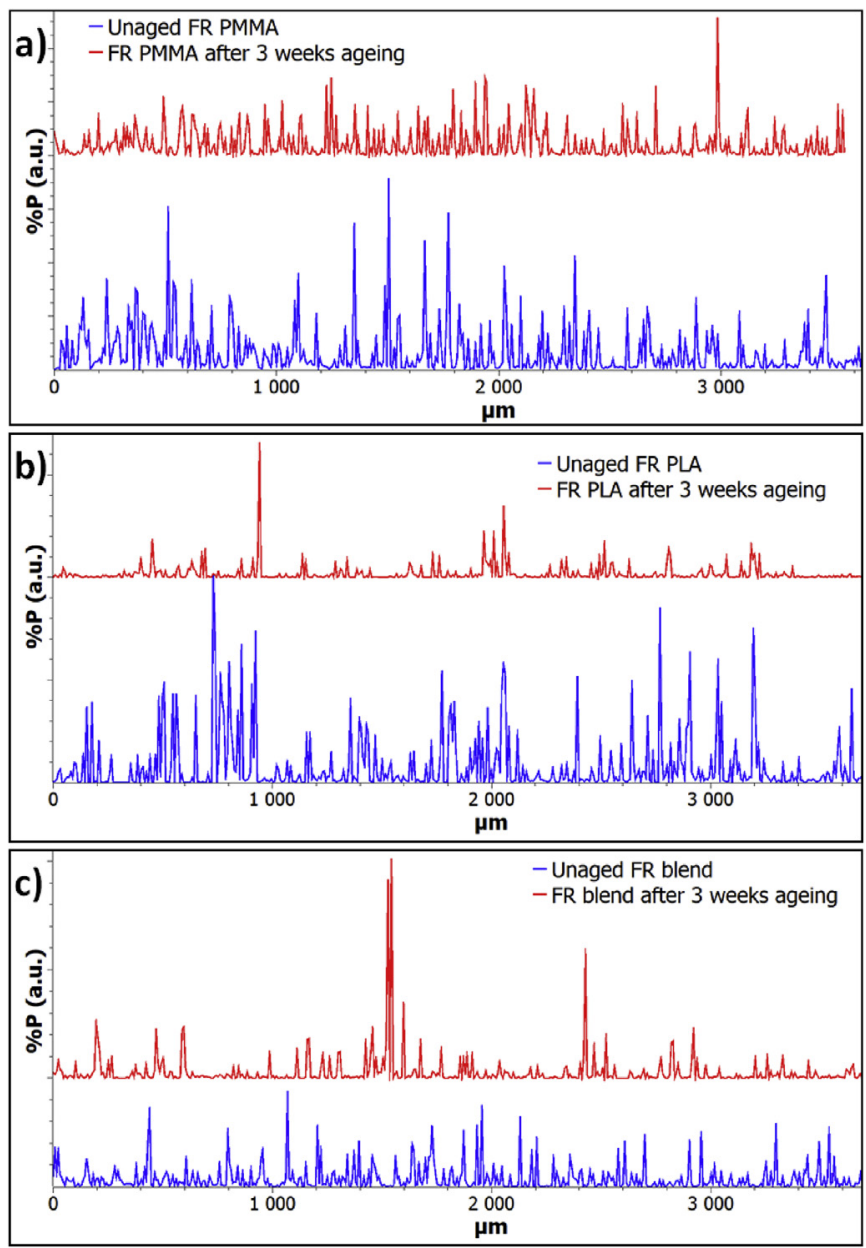

Fig. 18. EDX - phosphorus concentration along the sheet.

aged flame-retarded PMMA are shown in Fig. 19. Corresponding data are reported in Table 10. Unaged sample started to decompose at $338^{\circ} \mathrm{C}$ and left a char residue of $13 \mathrm{wt} \%$ at $800^{\circ} \mathrm{C}$. After 3 week ageing, a small decrease in the onset temperature happened, at $332{ }^{\circ} \mathrm{C}$, as well as a decrease of $3 \mathrm{wt} \%$ of the residue at $800^{\circ} \mathrm{C}$. These results confirm that the influence of ageing is limited.

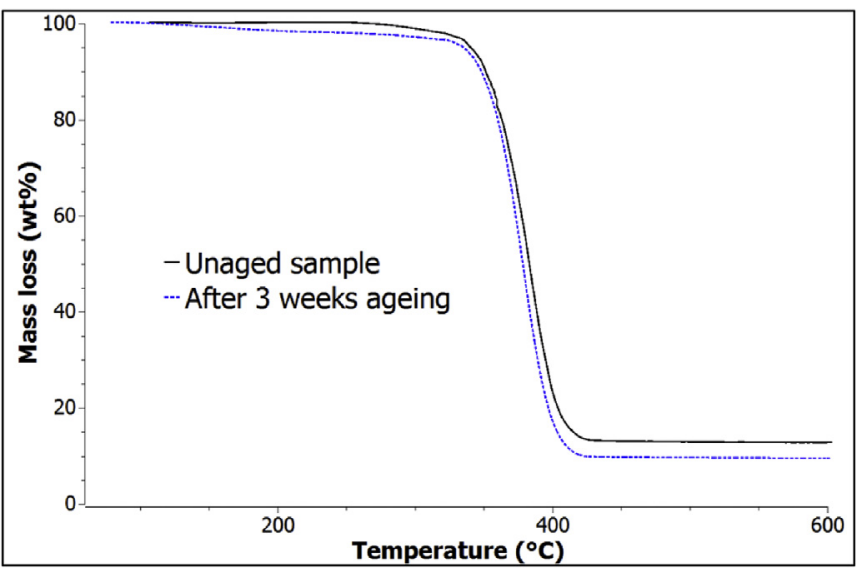

Fig. 19. TGA of unaged and aged flame-retarded PMMA under $\mathrm{N}_{2}$

The same analysis was performed on flame-retarded PLA. Results are shown in Fig. 20 and Table 10. First of all, no mass loss has been observed at $100{ }^{\circ} \mathrm{C}$, confirming a complete drying of the samples. Unaged sample started to decompose at $315^{\circ} \mathrm{C}$, and formed a char residue of $14 \mathrm{wt} \%$ at $800^{\circ} \mathrm{C}$. Thermal stability was affected by ageing. Onset degradation occurred $23^{\circ} \mathrm{C}$ earlier, at $292^{\circ} \mathrm{C}$; and the residue at $800^{\circ} \mathrm{C}$ was drastically decreased, at only $2 \mathrm{wt} \%$. Contrary to flame-retarded PMMA, ageing had a negative and huge impact on thermal stability.

Finally, analyses were carried out on the flame-retarded blend (Fig. 21, Table 10). Firstly, the onset temperature largely decreased with ageing time, from $311^{\circ} \mathrm{C}$ to $265^{\circ} \mathrm{C}$, revealing a degradation of the thermal stability. The degradation temperature at $50 \mathrm{wt} \%$ mass loss of the unaged sample was $369^{\circ} \mathrm{C}$; after ageing, this temperature slightly decreased at $360^{\circ} \mathrm{C}$. The char residue at $800^{\circ} \mathrm{C}$ of the unaged sample was $11 \% \mathrm{wt} \%$, and became $7 \mathrm{wt} \%$ after ageing, being between those of aged flame-retarded PMMA (10\%) and aged flame-retarded PLA (2\%).

\subsubsection{Flame retardant properties}

The influence of ageing on fire properties has been investigated by cone calorimetry. Samples were tested after different ageing times, and after complete drying. Specimens after cone tests are shown in Fig. 25, and all corresponding data are presented in Table 11. In order to check if the mass variations observed during ageing had an impact on the fire performances, the pHRR have been also calculated relatively to the sample masses before cone tests.

3.4.2.1. Flame-retarded PMMA. The Heat Release Rate (HRR) curves of flame-retarded PMMA are shown in Fig. 22. All samples showed a peak of heat release after around 130s of cone test. Then a plateau of heat release rate occurred between 160 and 380s. No major differences were observed after ageing: pHRR remained close to $400 \mathrm{~kW} / \mathrm{m}^{2}$, THR was comprised between 20 and $21 \mathrm{~kJ} / \mathrm{g}$, TTI was around 20s for all samples. The EHC was situated between 22 and $24 \mathrm{~kJ} / \mathrm{g}$, which is in accordance with the value obtained for the PMMA matrix. The residue at flame-out was $11 \%$ for all samples in 
Table 10

TGA data of unaged and aged formulations.

\begin{tabular}{|c|c|c|c|c|c|}
\hline Formulation & Ageing time & $\mathrm{T}_{\max }\left({ }^{\circ} \mathrm{C}\right)$ & $\mathrm{T}_{5 \mathrm{wt} \%}\left({ }^{\circ} \mathrm{C}\right)$ & $\mathrm{T}_{50 \text { wt } \%}\left({ }^{\circ} \mathrm{C}\right)$ & Char residues (wt\%) at $800{ }^{\circ} \mathrm{C}$ \\
\hline \multirow[t]{2}{*}{ FR PMMA } & Unaged sample & 379 & 338 & 381 & $13 \pm 2$ \\
\hline & 3 weeks & 376 & 332 & 376 & $10 \pm 2$ \\
\hline \multirow[t]{2}{*}{ FR PLA } & Unaged sample & 362 & 315 & 357 & $14 \pm 3$ \\
\hline & 3 weeks & 377 & 292 & 367 & $2 \pm 2$ \\
\hline \multirow[t]{2}{*}{ FR blend } & Unaged sample & $362-402$ & 311 & 369 & $11 \pm 2$ \\
\hline & 3 weeks & 360 & 265 & 360 & $7 \pm 2$ \\
\hline
\end{tabular}

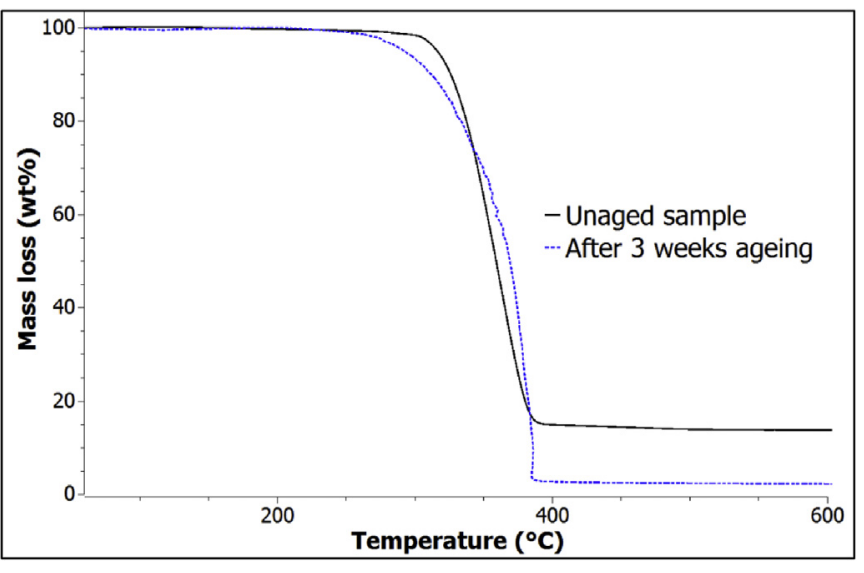

Fig. 20. TGA of unaged and aged flame-retarded PLA under $\mathrm{N}_{2}$.

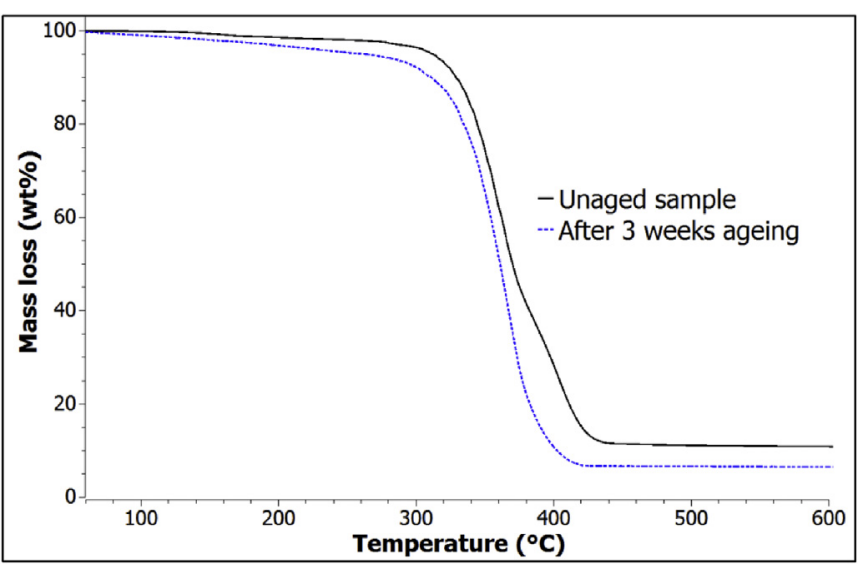

Fig. 21. TGA of unaged and aged flame-retarded blend under $\mathrm{N}_{2}$.

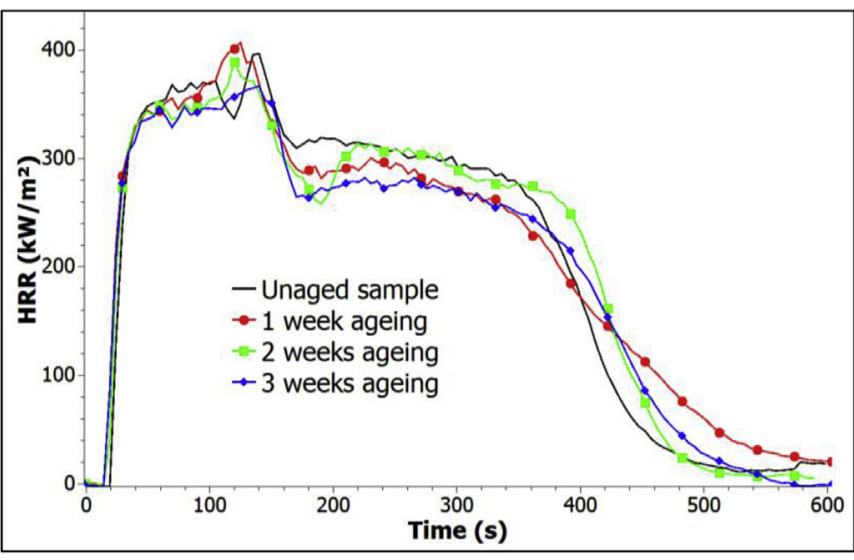

Fig. 22. HRR curves of flame-retarded PMMA at various ageing times.

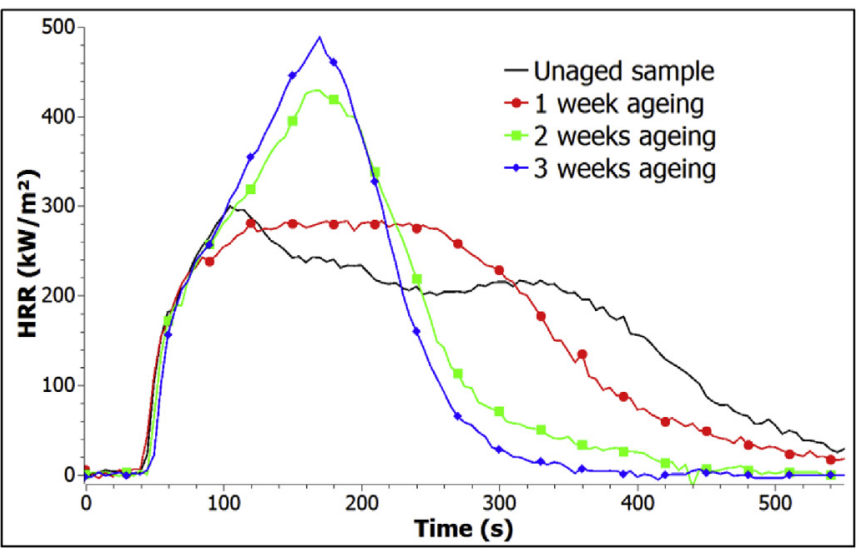

Fig. 23. HRR curves of flame-retarded PLA at various ageing times.

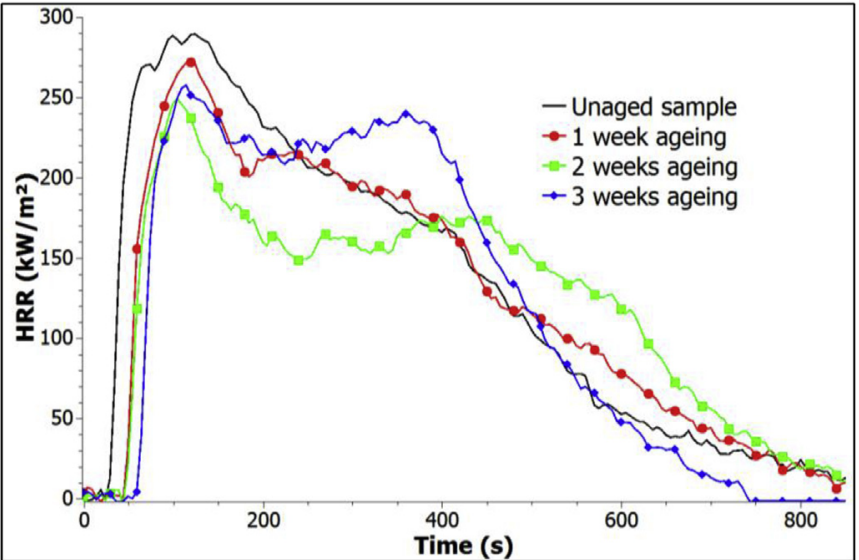

Fig. 24. HRR curves of flame-retarded blend at various ageing times.

good agreement with TGA results and did not show significant visual modifications. Consequently, the immersion into hot water did not have a significant impact on the fire properties of flameretarded PMMA.

3.4.2.2. Flame-retarded PLA. Unaged sample and 1 week aged sample exhibited moderate HRR values with a plateau which can be attributed to a barrier effect occurring between 100 and $300 \mathrm{~s}$ (Fig. 23), and more pronounced for the unaged sample. Differences appeared from 2 weeks of ageing with no more barrier effect since a strong pHRR was observed after $160 \mathrm{~s}$ at $460 \mathrm{~kW} / \mathrm{m}^{2}$. This peak reached $487 \mathrm{~kW} / \mathrm{m}^{2}$ after 3 weeks of ageing. A strong mass loss was observed during ageing; thus the pHRR have been calculated relatively to the initial mass. The same conclusion was observed, with a pHRR increase from 5.4 to $13.5 \mathrm{~kW} / \mathrm{g} \cdot \mathrm{m}^{2}$. At the same time, the time to flame out decreased with ageing time: ageing induced a shorter combustion, but more intensive. The residue at flame out 


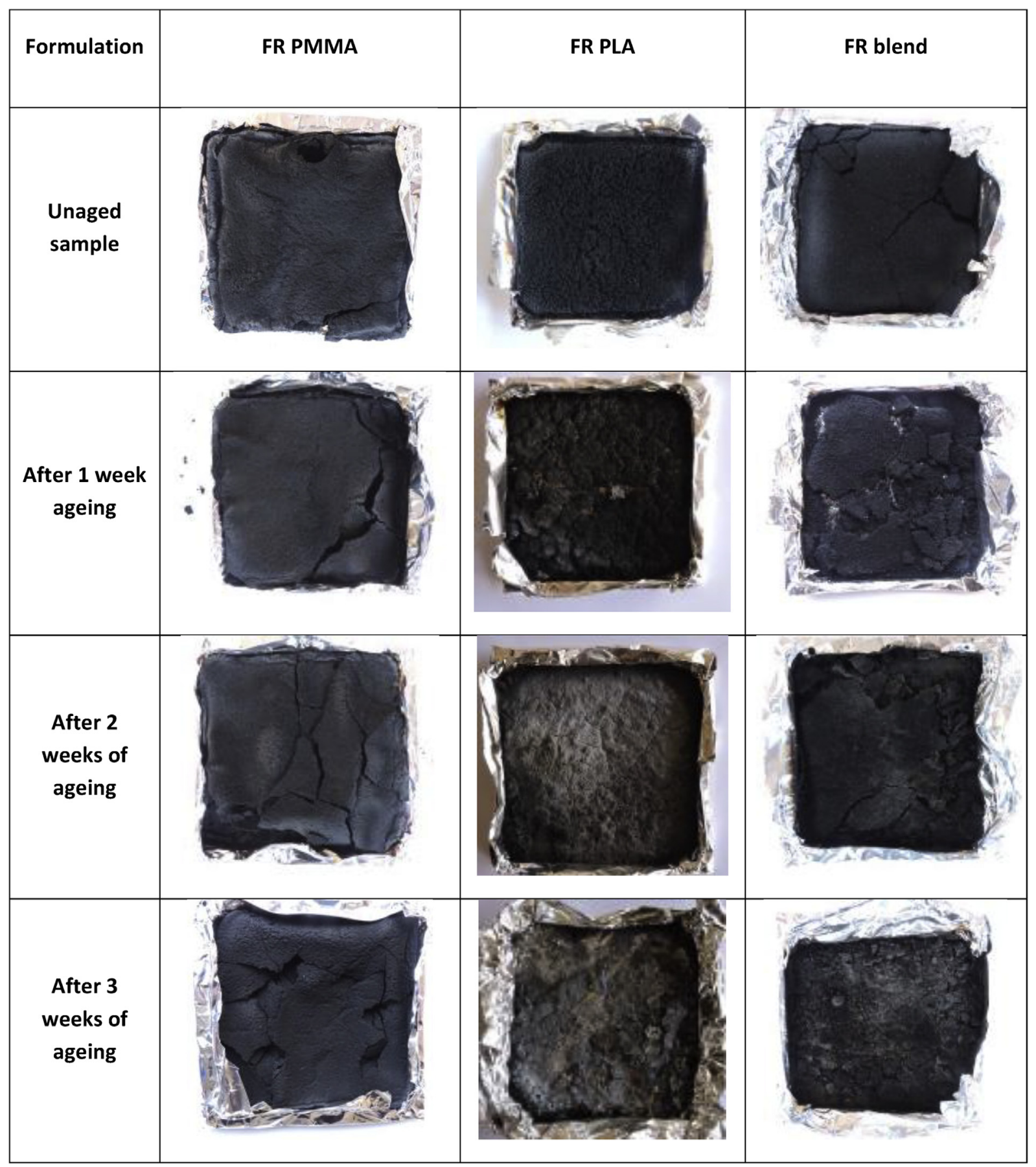

Fig. 25. Residues after cone calorimetry.

decreased drastically with ageing time, from $11.7 \%$ for the unaged sample to 3.5\% after 3 weeks of ageing in good agreement with TGA measurements. The residues were clearly less compact after ageing (Fig. 25). Contrary to flame-retarded PMMA, ageing had a negative impact on fire properties of PLA composite and it is considered that the loss of phosphorus after ageing was responsible for this loss of fire performance. Regarding THR, TTI and EHC, only small variations were noticed with ageing time.

3.4.2.3. Flame-retarded blend. Flame-retarded blends showed an increase in their time to ignition after ageing, from $28 \mathrm{~s}$ for the unaged sample to 50 s for sample aged for 3 weeks. Such an increase is unexpected and further investigations are needed. While APP (and other phosphorus flame retardants) usually leads to earlier TTI, the loss of phosphorus especially close to the sample surface may explain this increase. Another explanation could be the volatilisation of PLA chains that may have been restricted by the presence of PMMA. Concerning PHRR, no significant differences were observed: all samples showed approximately the same values (between 250 and $289 \mathrm{~kW} / \mathrm{m}^{2}$ ). But the shape of HRR was modified with ageing time (Fig. 24). The unaged sample developed a large pHRR, between 100 and 150s, followed by a regular decrease of HRR up to flame out. After 1 week of ageing, the pHRR had almost the same intensity, but became shorter. Then the HRR was almost constant between 200 and 300s, before a decrease similar to that of unaged sample. After 2 weeks of ageing, the phenomenon is more 
Table 11

Cone calorimetry parameters for flame-retarded formulations.

\begin{tabular}{|c|c|c|c|c|c|c|c|}
\hline Formulation & Ageing time & $\operatorname{pHRR}\left(\mathrm{kW} / \mathrm{m}^{2}\right)$ & pHRR (kW/g.m²) & THR $(\mathrm{kJ} / \mathrm{g})$ & TTI (s) & $\mathrm{EHC}(\mathrm{kJ} / \mathrm{g})$ & Residue at flame out (\%) \\
\hline \multirow[t]{4}{*}{ FR PMMA } & Unaged sample & 402 & 7.6 & 20.9 & 22 & 23.7 & 11.5 \\
\hline & Aged (1 week) & 407 & 7.6 & 20.7 & 18 & 23.5 & 10.8 \\
\hline & Aged (2 weeks) & 389 & 7.1 & 20.2 & 20 & 22.8 & 10.7 \\
\hline & Aged ( 3 weeks) & 373 & 6.7 & 19.6 & 18 & 22.2 & 10.7 \\
\hline \multirow[t]{4}{*}{ FR PLA } & Unaged sample & 291 & 5.4 & 14.4 & 40 & 16.4 & 11.7 \\
\hline & Aged (1 week) & 297 & 6.3 & 16.2 & 36 & 17.4 & 5.6 \\
\hline & Aged (2 weeks) & 460 & 11.5 & 16.2 & 44 & 17.2 & 4.3 \\
\hline & Aged (3 weeks) & 487 & 13.5 & 16.6 & 41 & 17.2 & 3.5 \\
\hline \multirow[t]{4}{*}{ FR blend } & Unaged sample & 289 & 5.4 & 17.8 & 28 & 20.4 & 12.9 \\
\hline & Aged (1 week) & 281 & 4.8 & 16.8 & 40 & 18.6 & 12.3 \\
\hline & Aged (2 weeks) & 250 & 4.2 & 16.0 & 48 & 18.3 & 11.9 \\
\hline & Aged ( 3 weeks) & 266 & 4.6 & 16.3 & 50 & 18.2 & 10.6 \\
\hline
\end{tabular}

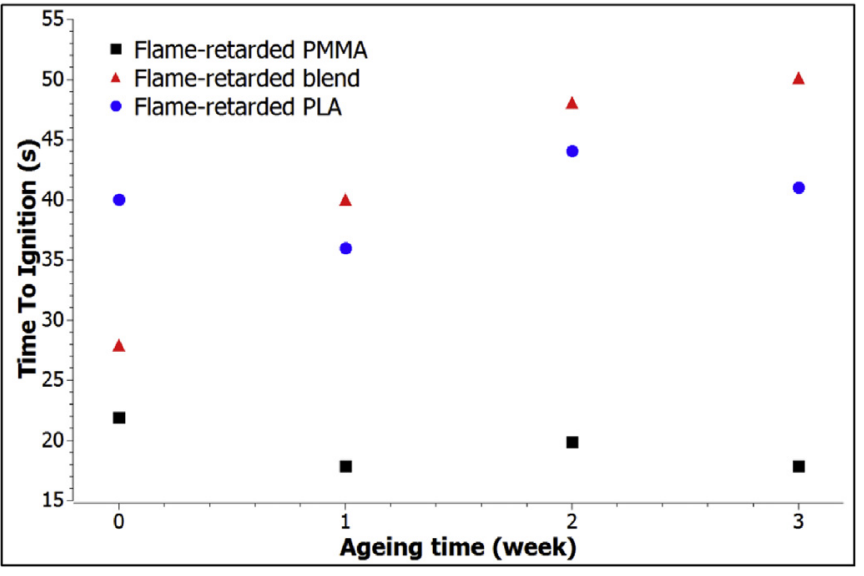

Fig. 26. Comparison of TTI of the 3 flame-retarded formulations.

pronounced, with a plateau of HRR occurring between 200 and 450s. The most aged sample showed a similar HRR plateau between 200 and 400s, but at higher HRR value and followed by the strongest decrease. Concerning the residue, it became less compact after ageing. The residue at flame out showed a slight decrease after 3 weeks of ageing, from $12.9 \%$ to $10.6 \%$. This reduction can be explained by the loss of phosphorus observed after ageing.

3.4.2.4. Comparison between the three polymeric matrices. The time to ignition of the 3 flame-retarded blends has been compared (Fig. 26). Only small variations (less than $2 \mathrm{~s}$ ) were obtained for each kind of specimens, revealing good repeatability. For each ageing time, time to ignition of flame-retarded PMMA was the lowest, and did not change significantly with ageing time. TTI of flame-retarded PLA was higher, but remained stable too after ageing. Conversely, flame-retarded blend showed an increase in its TTI with ageing time which was the highest after ageing.

The pHRR have also been compared (Fig. 27). Ageing did not have impact on flame-retarded PMMA, with a pHRR being stable at around $400 \mathrm{~kW} / \mathrm{m}^{2}$. This parameter increased strongly for flameretarded PLA, having the highest value after more than 2 weeks of ageing. Flame-retarded blend had the lowest pHRR at each ageing time, even showing a slight decrease after 2 and 3 weeks of ageing, evidencing the protective impact of PMMA against ageing.

\section{Conclusion}

This study was focused on the impact of ageing on flame retardant formulations, based on PLA, PMMA and a blend PLA/

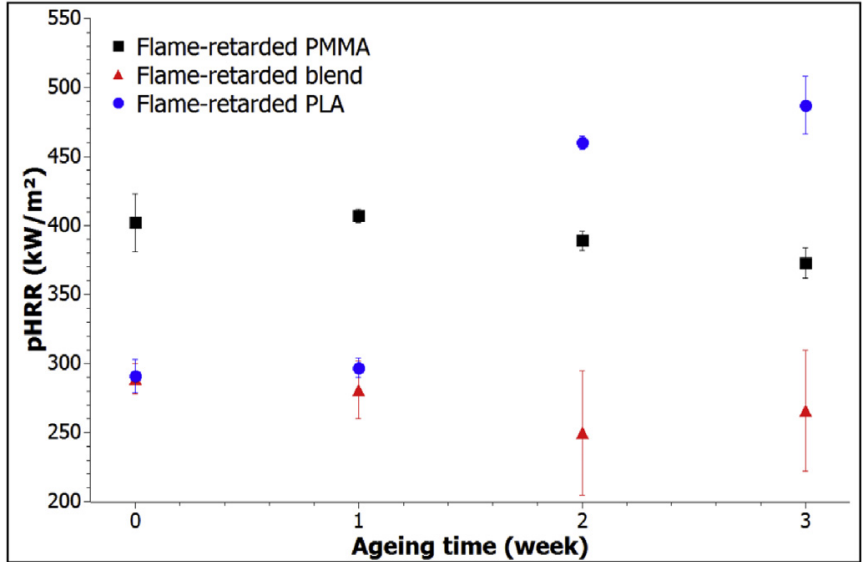

Fig. 27. Comparison of pHRR of the 3 flame-retarded formulations.

PMMA. Firstly, miscibility of the blend was demonstrated by means of DSC characterizations. When 50 wt\% PMMA was added, PLA crystallization was almost completely hindered, due to an important decrease of the crystallization kinetics. During ageing, crystallization phenomenon occurred leading to high crystallization rate. Impact of ageing was significantly different according to the polymeric matrix. Flame-retarded PMMA revealed only a limited impact on its morphological, thermal and fire properties. The case of flame-retarded PLA was very different, showing an important decrease of mechanical properties which can be ascribed to hydrolysis, and a degradation of thermal stability and fire reaction, due to the phosphorus loss during ageing. Residue at flame-out was clearly decreased, from $11.7 \%$ to $3.5 \%$. The flame-retarded blend showed intermediate properties. Incorporation of PMMA into flame-retarded PLA greatly improved its resistance to water, by restricting the FRs migration, leading to a moderate phosphorus loss, a small decrease of residue at flame-out, and only few variations of fire properties.

\section{Acknowledgements}

The authors wish to thank the Region Lorraine for funding this $\mathrm{PhD}$ thesis. They also thank the "Plastinnov" technological platform and C2MA members for their technical assistance and discussion.

\section{Appendix A. Supplementary data}

Supplementary data related to this article can be found at https://doi.org/10.1016/j.polymdegradstab.2018.07.008. 


\section{References}

[1] European Bioplastics, nova-Institute. Global Production Capacities of Bioplastics, 2016.

[2] 12th European Bioplastics Conference - Berlin. Bioplastics Are Doing the Difference, 2017.

[3] L.-T. Lim, R. Auras, M. Rubino, Processing technologies for poly(lactic acid), Prog. Polym. Sci. 33 (8) (2008) 820-852.

[4] R. Auras, B. Harte, S. Selke, An overview of polylactides as packaging materials, Macromol. Biosci. 4 (9) (2004) 835-864.

[5] Shen, Haufe, Patel, Product Overview and Market Projection of Emerging Biobased Plastics, Copernicus Institute for Sustainable Development and Innovation: Utrecht University, 2009.

[6] M.E. Mngomezulu, M.J. John, V. Jacobs, A.S. Luyt, Review on flammability of biofibres and biocomposites, Carbohydr. Polym. 111 (2014) 149-182.

[7] M. Jamshidian, E.A. Tehrany, M. Imran, M. Jacquot, S. Desobry, Poly-lactic acid: production, applications, nanocomposites, and release studies, Compr. Rev. Food Sci. Food Saf. 9 (5) (2010) 552-571.

[8] Y. Chen, L.M. Geever, J.A. Killion, J.G. Lyons, C.L. Higginbotham, D.M. Devine, Review of multifarious applications of poly (lactic acid), Polym. Plast. Technol. Eng. 55 (10) (2016) 1057-1075.

[9] P.G. Seligra, M. Lamanna, L. Famá, PLA-fmwcnt bionanofilms with high modulus and great properties to apply in packaging and biomedicine, Procedia Mater. Sci. 8 (2015) 383-390.

[10] X. Tian, T. Liu, C. Yang, Q. Wang, D. Li, Interface and performance of 3D printed continuous carbon fiber reinforced PLA composites, Composer Part Appl. Sci. Manuf. 88 (2016) 198-205.

[11] R. Hashemi Sanatgar, C. Campagne, V. Nierstrasz, Investigation of the adhesion properties of direct 3D printing of polymers and nanocomposites on textiles: effect of FDM printing process parameters, Appl. Surf. Sci. 403 (2017) $551-563$.

[12] S.G. Mosanenzadeh, S. Khalid, Y. Cui, H.E. Naguib, High thermally conductive PLA based composites with tailored hybrid network of hexagonal boron nitride and graphene nanoplatelets, Polym. Compos. 37 (7) (2016) 2196-2205.

[13] A. Bouzouita, Elaboration of Polylactide-based Materials for Automotive Application: study of Structure-process-Properties Interactions, PhD. Thesis, University of Valenciennes, Valencienne, 2016.

[14] A.K. Bledzki, A. Jaszkiewicz, Mechanical performance of biocomposites based on PLA and PHBV reinforced with natural fibres - a comparative study to PP Compos. Sci. Technol. 70 (12) (2010) 1687-1696.

[15] D.J. Cole-Hamilton, Nature's polyethylene, Angew. Chem. Int. Ed. 49 (46) (2010) 8564-8566.

[16] R.A. Auras, S.P. Singh, J.J. Singh, Evaluation of oriented poly(lactide) polymers vs. Existing PET and oriented PS for fresh food service containers, Packag. Technol. Sci. 18 (4) (2005) 207-216.

[17] D.E. Henton, P. Gruber, J. Lunt, J. Randall, Polylactic acid technology, Nat. Fibers Biopolym. Biocomposites 16 (2005) 527-577.

[18] Helou Penu, Acide polylactique (PLA), Tech. Ing. (2017). AM 3317 V1.

[19] A.-F. Mohd-Adnan, H. Nishida, Y. Shirai, Evaluation of kinetics parameters for poly(l-lactic acid) hydrolysis under high-pressure steam, Polym. Degrad. Stabil. 93 (6) (2008) 1053-1058.

[20] C.S. Proikakis, N.J. Mamouzelos, P.A. Tarantili, A.G. Andreopoulos, Swelling and hydrolytic degradation of poly (D, l-lactic acid) in aqueous solutions, Polym. Degrad. Stabil. 91 (3) (2006) 614-619.

[21] L.-L. Wei, D.-Y. Wang, H.-B. Chen, L. Chen, X.-L. Wang, Y.-Z. Wang, Effect of a phosphorus-containing flame retardant on the thermal properties and ease of ignition of poly(lactic acid), Polym. Degrad. Stabil. 96 (9) (2011) 1557-1561.

[22] M.F. Gonzalez, R.A. Ruseckaite, T.R. Cuadrado, Structural changes of polylacticacid (PLA) microspheres under hydrolytic degradation, J. Appl. Polym. Sci. 71 (8) (1999) 1223-1230.

[23] S.J. De Jong, E.R. Arias, D.T.S. Rijkers, C.F. Van Nostrum, J.J. Kettenes-Van den Bosch, W.E. Hennink, New insights into the hydrolytic degradation of poly (lactic acid): participation of the alcohol terminus, Polymer 42 (7) (2001) 2795-2802.

[24] J.R. Rocca-Smith, N. Chau, D. Champion, C.-H. Brachais, E. Marcuzzo, A. Sensidoni, F. Piasente, T. Karbowiak, F. Debeaufort, Effect of the state of water and relative humidity on ageing of PLA films, Food Chem. 236 (2017) 109-119.

[25] Y. Aso, S. Yoshioka, A. Li Wan Po, T. Terao, Effect of temperature on mechanisms of drug release and matrix degradation of poly (D,L-Lactide) microspheres, J. Contr. Release 31 (1994) 33-39.

[26] Tsuji, Ikarashi Nakahara, Poly(L-Lactide) high-temperature hydrolysis of poly(l-lactide) films with different crystallinities and crystalline thicknesses in phosphate-buffered solution, Macromol. Mater. Eng. 286 (2001) 398-406.

[27] G. Zhang, J. Zhang, S. Wang, D. Shen, Miscibility and phase structure of binary blends of polylactide and poly(methyl methacrylate), J. Polym. Sci., Part B: Polym. Phys. 41 (1) (2003) 23-30.

[28] M. Canetti, A. Cacciamani, F. Bertini, Miscible blends of polylactide and pol$\mathrm{y}$ (methyl methacrylate): morphology, structure, and thermal behavior J. Polym. Sci., Part B: Polym. Phys. 52 (17) (2014) 1168-1177.
[29] T. Shirahase, Y. Komatsu, Y. Tominaga, S. Asai, M. Sumita, Miscibility and hydrolytic degradation in alkaline solution of poly(l-lactide) and poly(methyl methacrylate) blends, Polymer 47 (13) (2006) 4839-4844.

[30] G. Rapp, C. Samuel, J. Odent, J.-M. Raquez, P. Dubois, P.-O. Bussière, J.L. Gardette, S. Therias, Peculiar effect of stereocomplexes on the photochemical ageing of PLA/PMMA blends, Polym. Degrad. Stabil. 150 (2018) 92-104.

[31] Arkema. Biopolymers Rnew - Altuglas $₫$ Resins.

[32] H. Vahabi, R. Sonnier, L. Ferry, Effects of ageing on the fire behaviour of flameretarded polymers: a review, Polym. Int. 64 (3) (2015) 313-328.

[33] M. Jimenez, S. Bellayer, B. Revel, S. Duquesne, S. Bourbigot, Comprehensive study of the influence of different aging scenarios on the fire protective behavior of an epoxy based intumescent coating, Ind. Eng. Chem. Res. 52 (2) (2013) 729-743.

[34] M. Aubert, C.-E. Wilén, R. Pfaendner, S. Kniesel, H. Hoppe, M. Roth, Bis (1propyloxy-2, 2, 6, 6-tetramethylpiperidin-4-Yl)-diazene-an innovative multifunctional radical generator providing flame retardancy to polypropylene even after extended artificial weathering, Polym. Degrad. Stabil. 96 (3) (2011) 328-333.

[35] A. Torikai, H. Kato, K. Fueki, Y. Suzuki, F. Okisaki, M. Nagata, Photodegradation of polymer materials containing flame-cut agents, J. Appl. Polym. Sci. 50 (12) (1993) 2185-2190.

[36] Torikai, Takahiro, Fumio, Photodegradation of polystyrene containing flame retardants: effect of chemical structure of the additives on the efficiency of degradation, J. Appl. Polym. Sci. 67 (1998) 1293-1300.

[37] U. Braun, V. Wachtendorf, A. Geburtig, H. Bahr, B. Schartel, Weathering resistance of halogen-free flame retardance in thermoplastics, Polym. Degrad. Stabil. 95 (12) (2010) 2421-2429.

[38] N. Lesaffre, S. Bellayer, G. Fontaine, M. Jimenez, S. Bourbigot, Revealing the impact of ageing on a flame retarded PLA, Polym. Degrad. Stabil. 127 (2016) $88-97$.

[39] N. Lesaffre, S. Bellayer, H. Vezin, G. Fontaine, M. Jimenez, S. Bourbigot, Recent advances on the ageing of flame retarded PLA: effect of UV-light and/or relative humidity, Polym. Degrad. Stabil. 139 (2017) 143-164.

[40] C. Feng, M. Liang, Y. Zhang, J. Jiang, J. Huang, H. Liu, Synergistic effect of lanthanum oxide on the flame retardant properties and mechanism of an intumescent flame retardant PLA composites, J. Anal. Appl. Pyrolysis 122 (2016) 241-248.

[41] S. Solarski, F. Mahjoubi, M. Ferreira, E. Devaux, P. Bachelet, S. Bourbigot, R. Delobel, P. Coszach, M. Murariu, A. Da silva Ferreira, et al., (Plasticized) polylactide/clay nanocomposite textile: thermal, mechanical, shrinkage and fire properties, J. Mater. Sci. 42 (13) (2007) 5105-5117.

[42] H. Zhu, Q. Zhu, J. Li, K. Tao, L. Xue, Q. Yan, Synergistic effect between expandable graphite and ammonium polyphosphate on flame retarded polylactide, Polym. Degrad. Stabil. 96 (2) (2011) 183-189.

[43] Y. Chen, W. Wang, Y. Qiu, L. Li, L. Qian, F. Xin, Terminal group effects of phosphazene-triazine Bi-Group flame retardant additives in flame retardant polylactic acid composites, Polym. Degrad. Stabil. 140 (2017) 166-175.

[44] N.A. Isitman, M. Dogan, E. Bayramli, C. Kaynak, The role of nanoparticle geometry in flame retardancy of polylactide nanocomposites containing aluminium phosphinate, Polym. Degrad. Stabil. 97 (8) (2012) 1285-1296.

[45] E.L. Teoh, M. Mariatti, W.S. Chow, Thermal and flame resistant properties of poly (lactic acid)/poly (methyl methacrylate) blends containing halogen-free flame retardant, Procedia Chem. 19 (2016) 795-802.

[46] E.L. Teoh, W.S. Chow, M. Jaafar, $\beta$-cyclodextrin as a partial replacement of phosphorus flame retardant for poly(lactic acid)/poly(methyl methacrylate): a more environmental friendly flame-retarded blends, Polym. Plast. Technol. Eng. (2017) 1-15.

[47] E.W. Fischer, H.J. Sterzel, G. Wegner, Investigation of the structure of solution grown crystals of lactide copolymers by means of chemical reactions, KolloidZ. Z. Polym. 251 (11) (1973) 980-990.

[48] M. Gonzalez-Garzon, S. Shahbikian, M.A. Huneault, Properties and phase structure of melt-processed PLA/PMMA blends, J. Polym. Res. 25 (2) (2018).

[49] C. Samuel, J.-M. Raquez, P. Dubois, PLLA/PMMA blends: a shear-induced miscibility with tunable morphologies and properties? Polymer 54 (15) (2013) 3931-3939.

[50] Z.X. Teo, W.S. Chow, Impact, thermal, and morphological properties of pol$\mathrm{y}$ (lactic acid)/poly(methyl methacrylate)/halloysite nanotube nanocomposites, Polym. Plast. Technol. Eng. 55 (14) (2016) 1474-1480.

[51] E. Rodriguez, S. Shahbikian, B. Marcos, M.A. Huneault, Hydrolytic stability of polylactide and poly(methyl methacrylate) blends, J. Appl. Polym. Sci. (2017) 45991.

[52] R.-Y. Bao, W. Yang, Z.-Y. Liu, B.-H. Xie, M.-B. Yang, Polymorphism of a highmolecular-weight racemic poly(l-lactide)/poly(d-lactide) blend: effect of melt blending with poly(methyl methacrylate), RSC Adv. 5 (25) (2015) $19058-19066$.

[53] T.-M. Wu, C.-Y. Wu, Biodegradable poly(lactic acid)/chitosan-modified montmorillonite nanocomposites: preparation and characterization, Polym. Degrad. Stabil. 91 (9) (2006) 2198-2204.

[54] K. Das, D. Ray, I. Banerjee, N.R. Bandyopadhyay, S. Sengupta, A.K. Mohanty, M. Misra, Crystalline morphology of PLA/clay nanocomposite films and its 
correlation with other properties, J. Appl. Polym. Sci. 118 (1) (2010) 143-151.

[55] S. Barrau, C. Vanmansart, M. Moreau, A. Addad, G. Stoclet, J-M. Lefebvre, R. Seguela, Crystallization behavior of carbon Nanotube-Polylactide nanocomposites, Macromolecules 44 (16) (2011) 6496-6502.

[56] G. Liu, W. Chen, J. Yu, A novel process to prepare ammonium polyphosphate with crystalline form II and its comparison with melamine polyphosphate, Ind. Eng. Chem. Res. 49 (23) (2010) 12148-12155.
[57] K. Wu, Y. Zhang, W. Hu, J. Lian, Y. Hu, Influence of ammonium polyphosphate microencapsulation on flame retardancy, thermal degradation and crystal structure of polypropylene composite, Compos. Sci. Technol. 81 (2013) 17-23.

[58] B. Wang, K. Zhao, Y. Zhang, Y. Tao, X. Zhou, L. Song, G. Jie, Y. Hu, Influence of aging conditions on the mechanical properties and flame retardancy of HIPS composites, J. Appl. Polym. Sci. (2018) 46339. 